Calibration of Seismic Attributes for Reservoir Characterization

\author{
Annual Report \\ Reporting Period Start Date: October 1, 1998 \\ Reporting Period End Date: September 30, 1999 \\ Principal Author: Wayne D. Pennington \\ Date of Issue of Report: November 1999
}

DOE Award Number DE-AC26-98BC15135

\author{
Submitted by: \\ Wayne D. Pennington \\ Department of Geological Engineering and Sciences \\ Michigan Technological University \\ 1400 Townsend Drive \\ Houghton, MI 49931
}




\section{Disclaimer}

This report was prepared as an account of work sponsored by an agency of the United States Government. Neither the United States nor any agency thereof, nor any of their employees, makes any warranty, express or implied, or assumes any legal liability or responsibility of the accuracy, completeness, or usefulness of any information, apparatus, product, or process disclosed, or represents that its use would not infringe privately owned rights. Reference herein to any specific commercial product, process, or service by trade name, trademark, manufacturer, or otherwise does not necessarily constitute or imply its endorsement, recommendation, or favoring by the Untied States Government or any agency thereof. The views and opinions of authors expressed herein do not necessarily state or reflect those of the United States Government or any agency thereof. 


\begin{abstract}
The project, "Calibration of Seismic Attributes for Reservoir Calibration," is on schedule after the first year of the contract. We have been working on multiple data sets, including two public-domain sets, one proprietary data set with a corporate partner, and one other proprietary data set as a member of a consortium. We have expanded the use of high-end software well beyond that anticipated in the original work plan, and now use, on a regular basis, The use of these high-end software packages has greatly enhanced our ability to identify, study, and evaluate potential attributes in the seismic data.
\end{abstract}

The data sets used in this project represent a wide variety of environments. One is the fluvial-channel depositional setting of the Stratton data set in South Texas, where the problem consists not only of recognizing the seismic response of a sand-filled channel, but separating it from the signature of interfering thin-beds, most of which are not productive. Another environment is the delta and shore-face setting of the Boonsville data set in North Texas, where karsting in deeper horizons has altered the local productivity of the shallower horizons under consideration. The Wamsutter area of Wyoming provides a very different example, one of a fairly tight formation in a thinbedded sequence; this data set is likely to be the most difficult to analyze in terms of seismic attributes. The Gulf of Mexico is one location where seismic-attribute analysis is fairly routine, and one of our data sets is from there: the Teal South field is the subject of a time-lapse study using multi-component ocean-bottom sensors; our study is concentrating (at first) on the legacy streamer data obtained prior to production from the field, with the intention of using the time-lapse results to confirm (or disprove) the physical basis of the attributes we study.

These data sets are being studied in a variety of manners. By the end of the second year of the project, all data sets will have undergone similar processing approaches to the evaluation of seismic attributes, but at this time we have begun by concentrating on what we consider to be the most promising techniques for each field. The Boonsville data set has been evaluated using 'conventional' seismic attributes, such as those that are based on Hilbert-transform techniques. The Stratton data set analysis has concentrated on the use of wavelet-shape classification techniques. Both Boonsville and Stratton have been analyzed using the Dynamic Fluid Method of TransSeismic International, in which a combination of differential instantaneous frequency and amplitude attributes remove what is presumed to be lithology effect, in an effort to identify effects due to pressure and open crack-shaped pores. The Wamsutter data set has been studied using geostatistical classification schemes, and has undergone some initial inspection with impedance inversion and wavelet-shape analysis. The analysis of the Teal South data set has so far been primarily based on impedance inversion and petrophysical predictions.

Although the use of simple attributes can often be found to correlate with reservoir properties of interest, our interpretations so far suggest that there are many pitfalls to be encountered. On the other hand, a knowledge-based model for interpretation of waveform character is likely to prove beneficial for attribute understanding and use. This knowledge base can come from forward modeling and/or inversion for volume properties. 


\section{Table of Contents}

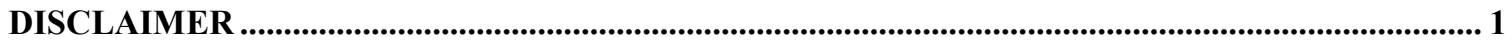

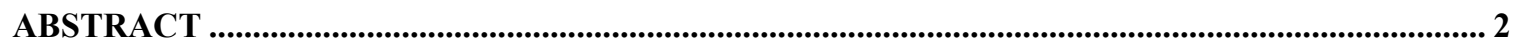

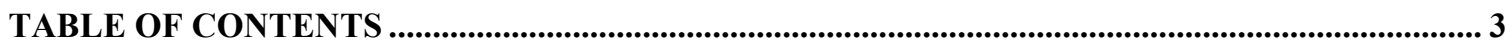

LIST OF GRAPHICAL MATERIALS: ................................................................................................... 4

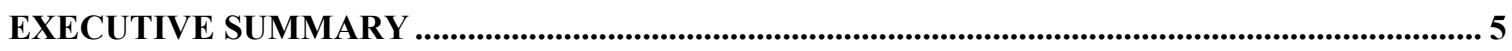

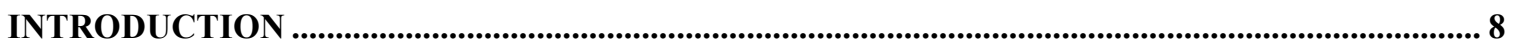

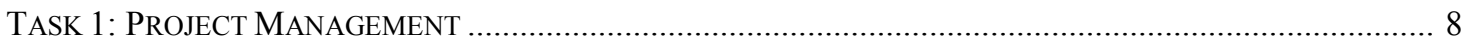

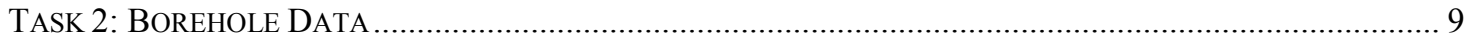

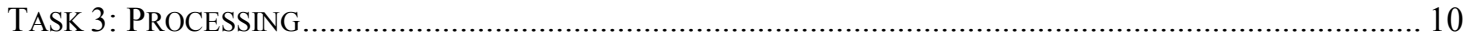

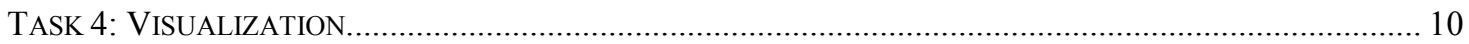

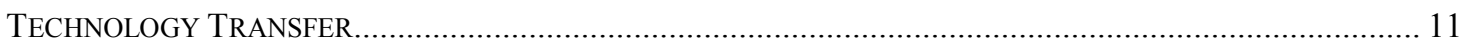

RESULTS AND DISCUSSION .............................................................................................................. 12

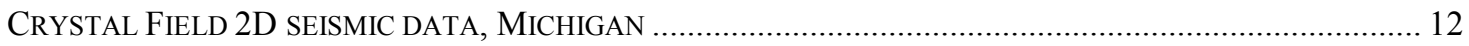

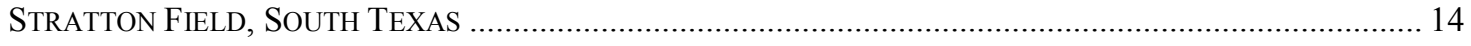

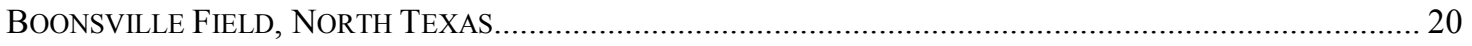

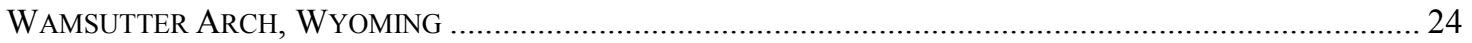

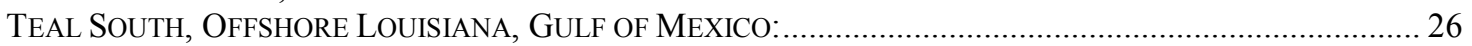

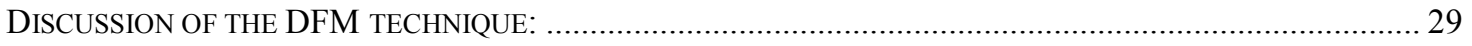

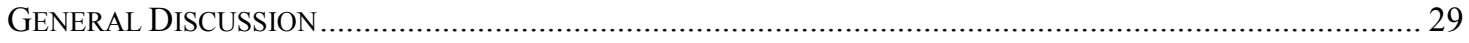

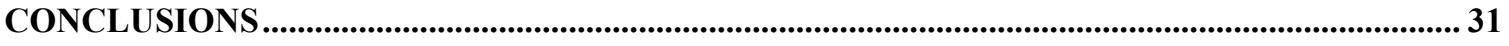

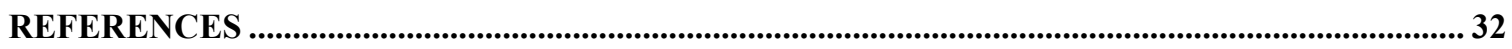

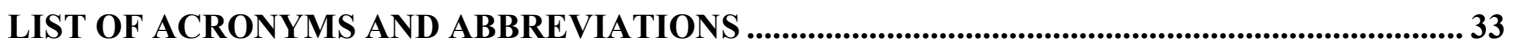




\section{List of Graphical Materials:}

Figure 1: Left side: A shot gather of the Crystal field data; Right side: a CMP gather.. 12

Figure 2: Three-dimensional view of a prestack 2-D line........................................... 13

Figure 3: Shallow horizon in Stratton data showing apparent stream channels............... 14

Figure 4: The same horizon as shown in Figure 3, from the Stratton data set ................ 15

Figure 5: Schematic diagram summarizing approach used by the Texas ....................... 16

Figure 6: Seismic facies classification map of an interval near $840 \mathrm{~ms}$ in Stratton data. 17

Figure 7: Cut-out region of channel, with detailed reclassification of facies ................. 17

Figure 8: A combination of time structure and facies classification. in Stratton data. ..... 17

Figure 9: DFM results for Stratton field along one inline............................................. 18

Figure 10: DFM results for Stratton field showing an apparent channel......................... 19

Figure 11: DFM results for Stratton field showing the block ...................................... 19

Figure 12: Caddo formation log-based classification scheme developed......................20

Figure 13: Map of tentative log-based classification scheme used in Boonsville. ...........21

Figure 14: Seismic waveshapes used in the seismic facies classification........................21

Figure 15: Seismic facies classification combined with log-based interpretation ...........22

Figure 16: Three-dimensional image of the DFM results for the Boonsville data ...........23

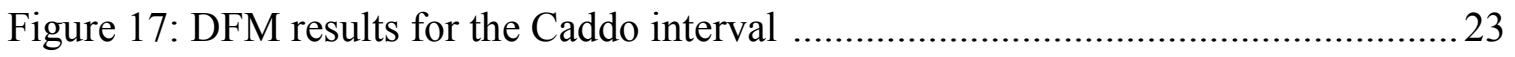

Figure 18: Location of the Wamsutter survey area ......................................................... 24

Figure 19: Schematic cross-section, showing the Wamsutter area of study....................25

Figure 20: Synthetic seismogram and stacked data from seismic volume......................26

Figure 21: Two histograms of specific simple attributes from the Wamsutter data. ........26

Figure 22: Three-dimensional image of a time-lapse difference volume. ....................... 27

Figure 23: Migrated and Inverted seismic data for Teal South......................................28 


\section{Executive Summary}

This project is intended to enhance our ability to use seismic data for the determination of rock and fluid properties through an improved understanding of the physics underlying the relationships between seismic attributes and formation. We have expanded our study to include four data sets, covering a variety of rock types and depositional environments; all of which are host to significant reserves in the domestic United States.

The first steps in performing any such study involve the basic interpretation of seismic data -- tracking horizons, correlating with wells, and identifying basic formation parameters. The next steps involve producing synthetic seismograms from well log data, analysis of statistical correlations between formation properties as determined by well logs or production characteristics, and then interpretation of the physical basis for such correlations, prediction of other correlations, and the testing of hypotheses through additional synthetic seismogram generation and modeling. In some cases, short-cuts can be taken through this sequence to begin interpretation of the data set at hand; but, eventually, the entire set of procedures must be followed for the reliable use of seismic data in reservoir characterization.

Our project has reached various stages in each of the data sets, and uses many different interpretation and analysis procedures on those data sets. Eventually, all of the analysis procedures will be used on all data sets, but we have started each interpretation with the 'short-cut' that seems most appropriate for that volume.

- An existing 2-D seismic line over Crystal field, MI, (where a Class II project was conducted) has been used to investigate the effect of seismic acquisition parameters on attribute analysis. We have loaded the prestack 2D data into a $3 \mathrm{D}$ visualization program to enhance this interpretation.

- The Wamsutter data from Wyoming has been reinterpreted along several horizons, providing an improved map of the formation, and we have begun using statistical analyses to detect differences in seismic character. Differences in seismic character between multiple data volumes in the same area led to some difficulties in confirming our seismic-to-well ties, but those have been overcome.

- The Stratton data from South Texas has been reinterpreted along several horizons, and has been used in preliminary statistical studies. It has been analyzed for waveform-shape classifications, and has been processed and interpreted by the DFM method through a subcontractor.

- The Boonsville data from North Texas has been reinterpreted along several horizons, and tentative conclusions have been drawn, using primarily 'conventional' seismic attributes, and has been processed and interpreted by the DFM method by a subcontractor.

- The Teal South data from offshore Louisiana in the Gulf of Mexico has been inverted for impedance. Appropriate well log data was not available during the time period covered by this report, so the inversion is currently band-limited, and not yet appropriate for lithology interpretation. Based on the PVT (Pressure-Volume- 
Temperature) analysis provided for a sample reservoir fluid and on the logs that were available, some significant conclusions about the expected seismic response of the reservoir during production were made.

We have also obtained high-end processing and interpretation software for use in this study. We now regularly use the following software products:

- GeoFrame software suite from Schlumberger GeoQuest for seismic interpretation and petrophysical analysis,

- iXL seismic processing software from Mercury International Technologies for prestack and poststack seismic processing,

- IC2 interactive cluster analysis software from Andrews Scott Pickford for geostatistical analysis,

- Stratimagic and NexModel wavelet-shape analysis programs from Flagship Geosciences for seismic facies classification, and

- Jason Geoscience Workbench inversion program from Jason GeoSystems for impedance inversion.

The availability of these programs has greatly enhanced our ability to investigate the seismic data and related wellbore, production, and geologic information for relationships and insight. As a result of the enhancement of the project by these programs and the large size of some of the data sets being studied, the project underwent some redirection of efforts in computer system administration and data management; this caused no change in the cost for the project.

Although 'conventional' seismic attributes have been used for some years in the interpretation of seismic data, their physical basis has not always been understood. The most basic attribute is amplitude, which is often related to porosity and fluid content through a simple reflection-coefficient and sonic-porosity argument; but we know it is also related to bed thickness through tuning, and this is a significant problem in thin-bed prospects. During production, too, the amplitude may change as a result of differing and competing effects, all of which result from a decrease in reservoir pressure: fluid saturation changes, liquid modulus changes, and dry frame modulus changes. The other seismic attributes are even more remotely related to the reservoir properties of interest, and are subject to significant ambiguity in their interpretation.

We should, perhaps, consider seismic attributes as 'proxies' for more-complex waveform phenomena that can, in turn, be related more directly to the reservoir properties of interest. For example, a seismic attribute that counts the number of zero-crossings between two mapped horizons may, in some instances, correlate well with some reservoir property. But it does so simply because the number of zero-crossings is determined by the wavelet character, and it is the wavelet character that is more closely related to the reservoir properties. It would be a mistake, in our opinion, to use an attribute such as this in developing a field unless its origin were completely known and understood. The matching of wavelet character can be accomplished through the combination of a few 
distinct attributes, and it can be accomplished through programs designed to match the entire wavelet over an interval. Some programs are commercially available which use sophisticated routines to classify wavelets within an interval in a seismic volume according to their similarity to each other; these programs can be run 'unsupervised,' which means that the classification is entirely automatic, without regard to user expectations of waveform types depending on the lithology or fluids present. Some can also be run in a 'supervised' mode, meaning that the classification is performed based on the waveforms a user is expecting to encounter. This latter approach is especially intriguing; it allows for the user to predict, based on well log data and other knowledge, the waveforms over a certain interval that should be expected for different conditions of interest, say, of fluid or porosity. The program then searches for the waveforms within the volume interval that most closely match those expected. It is important in this case to establish a very good seismic-to-well tie in one or more places within the volume.

The wavelet itself is not the answer; instead, we seek the formation properties of porosity, fluid content, etc. From seismic data, it is impossible to uniquely determine these properties directly, but there are approaches designed to improve our understanding of the reservoir. One of these is inversion of seismic data for impedance, which can often be related to porosity and fluid content, if other variables can be eliminated. Using poststack data alone, an investigator can carefully remove the effect of the wavelet and produce a 'band-limited' inverted volume - this volume shows the relative changes of impedance, in a certain frequency range depending on the frequency content of the seismic wavelet and the reflection series. By combining this information with the lowfrequency content of well-log information (converted from depth to time), we obtain a realistic volume of impedance values, from which porosity and/or fluid content may be inferred, within limits.

Subtle variations within the wavelet along given horizons may provide a highly precise picture of variations in the formation properties not directly related to lithology such as formation pressure. The DFM (Dynamic Fluid Method) approach has been applied to two of the data sets, and pictures of the inferred pressure regime in the subsurface have been derived. These results are still under investigation, and the method will soon be applied to other data sets.

Both the wavelet-classification schemes and the inversion approaches require an intimate knowledge of the seismic wavelet for reliable interpretation. Because most seismic data available to domestic operators, particularly for the investigation of older, more mature areas, is in the form of processed poststack data, we are concentrating on the applications available to treat this type of data, but incorporating prestack artifacts and features in our analysis. "Footprints" of data acquisition schemes may be present in the poststack volume, and amplitude-versus-offset effects may not be apparent in traditional inversion results, but may be extracted with appropriate knowledge of the rock types present. Much of our current effort is concentrated on optimizing the extraction of a consistent high-quality wavelet from the poststack seismic data, and making use of that wavelet in interpretation and modeling. 


\section{Introduction}

The objectives of this project are three-fold: To determine the physical relationships between seismic attributes and reservoir properties in specific field studies; to improve the usefulness of seismic data by strengthening the physical basis of the use of attributes; and, in the third year of the project, to test the approaches suggested or developed during the first two years on at least one new data set. In association with these studies, collaboration with corporate partners and technology transfer as ideas are developed and tested are ongoing integral components.

In order to start quickly on the project, we began with the analysis and interpretation of two public-domain data sets, Stratton and Boonsville, from the Texas Bureau of Economic Geology. [These data sets were made possible through earlier projects funded in part by the Department of Energy.] At the same time, we sought and obtained access to additional proprietary data sets through corporate partners, consisting of data from the Wamsutter Arch area of Wyoming through BPAmoco, and the Teal South field offshore Louisiana in the Gulf of Mexico, operated by Texaco, and studied as part of a consortium led by the Energy Research Clearing House. These data sets are now completely loaded and analysis underway. Concurrent with the start of this project, a number of highly sophisticated software programs were made available to our group, and additional programs were subsequently made available specifically to assist in this project.

The data sets have all been loaded, horizons tracked, and specialized studies of varying natures conducted on each one. The preliminary investigations of each data set is complete, and detailed, revised, and special analyses are underway. One theme in common with each data set is that the seismic-to-well tie must be improved over the initial attempt; this is a direct result of our conclusion that the most important aspect to identifying the physical nature of attributes recognized on seismic data is the quality of the well-tie and, in turn, the quality of the wavelet used to accomplish that tie.

This project is divided into four main tasks, and these are further subdivided into subtasks. The following sections refer to those tasks; when appropriate, the application of each task to each data set is described. The breakdown in the 'Results and Discussion' section of this report will be based not on tasks, but on the data sets and on the concepts derived from those data sets.

\section{Task 1: Project Management}

Project management encompasses reporting and project support. Reporting is essentially on schedule, and project support is back on schedule after some initial redirection of efforts. Because of the addition of high-end software to the project and the large sizes of the multiple data volumes we obtained, we required the services of a system administrator for about one-quarter time; but we had initially received such services for about one-third of that budgeted amount, and had to supplement those services with graduate student support and additional efforts from corporate partners, including those donating the software. An additional system administrator has been hired by a group of 
researchers, and our needs are now being fully met. Other aspects of Project Management have remained on track.

Training for some of the software packages has been accomplished by attending training courses conducted by the companies providing the software. To date, we have had members of our team take part in training on the following packages:

- GeoQuest GeoFrame products (five members have attended some training, covering three different courses, up to one week each, including Seismic Interpretation, Data Management, and Integrated Workflow),

- IC2 from Scott Pickford (a trainer from the company taught a two-day training course on the MTU campus, attended by eight members of our team and others),

- Stratimagic from Flagship Geosciences (two members attended a two-day course, and we are beta-testing a version of NexModel for use in the project),

- Jason GeoScience Workbench from Jason Geosystems (two members have attended the one-week training course in inversion).

\section{Task 2: Borehole Data}

Borehole data for this project consists of three types: existing data (of all sorts), new core and outcrop data (to determine fine-scale heterogeneities), and new log data acquired for this project. Only existing data was anticipated to be acquired during the first year of the project. As opportunities arose, we obtained new data during the first year anyway.

We have already received a significant amount of borehole data, both from the publicdomain data sets and from the proprietary ones. We have incorporated that into most of the software programs in use (see Task 4 for additional details), and have been using it in correlations with seismic data and in statistical analyses. Additional specific log and production data has been requested from the corporate partners, including the new operator of one of the public-domain data sets; permission to obtain these additional pieces of data has been granted, and some of it has already arrived at MTU.

Core from the Wamsutter study area became accessible in Tulsa, OK, because of an internal corporate study currently underway there. Our budget includes the purchase of a hand-held seismic velocity meter during year 2 of the project; in order to make measurements while the core was available, during year 1, we borrowed a similar device (from Mike Batzle at Colorado School of Mines), and spent two days in the core facility making measurements in different directions on the core. Those data are being incorporated into our project, and have been provided to the corporate partner as well. Additional fine-scale permeability data was made available from cores in or near the study area, and other laboratory measurements have been provided to us. We also found that a colleague at Michigan Tech, Debu Misra, has been involved with outcrop studies of the formation under review in the Wamsutter area (the Almond formation), and have received copies of the raw (un-normalized and normalized) data for permeability and other properties from those outcrop studies. These have been used in some geostatistical efforts still underway. 
Production details from the Stratton field were needed to make better sense of the observations there; these data (completions records and initial flow rates) were provided by the new field operator, and are being incorporated into our studies. In this field, the production occurs from many different intervals, and may or may not occur within a specific interval in any given well, depending on the nature of the rocks encountered there. The field has been producing for many decades, with a series of recompletions conducted to tap new pay at a number of different times. The detailed completions history of each well is required to make sense of the production summaries and the link to seismic attributes.

The Teal South field in the Gulf of Mexico incorporates more than one pay sand; we have PVT data from samples taken from one of those pay sands, and partial logs from some of the wells that produce from one of the reservoirs. The information at hand made it clear that the fluid properties differ among the various pay sands, and the logs indicate that local heterogeneity can not be ignored. As a result of these findings, the operator has agreed to provide additional log data. Some of the logs available include dipole sonic data, which may prove critical to understanding the nature of the attributes in this classic bright-spot environment.

\section{Task 3: Processing}

We have conducted most of the processing of data that is required at MTU, using software provided by donors; additional processing (for the DFM technique) has been conducted by a subcontractor. We are finalizing negotiations with another donor for additional software which will enhance our processing capabilities, and new features being provided in updates to existing software will provide some other algorithms of value to the project. Extensive use of spreadsheet programs has also been made in order to model the effects of fluid and pressure changes during production (see later discussion for details).

To date, our processing efforts have included the following:

- prestack processing of a 2D line to evaluate acquisition artifacts,

- poststack processing for attribute extraction,

- poststack processing for similarity/coherence, and

- poststack inversion for acoustic impedance.

\section{Task 4: Visualization}

In our project organization, visualization includes the massive effort of data management as well as the specific techniques for visualization. The database management is under control, and has benefited greatly from additional system administration support. We have added hard drives and other networked devices as appropriate to manage the large data sets, and have upgraded some of our software suites to enable improved sharing of data and interpretation. We have been able to utilize the $3 \mathrm{D}$ visualization capabilities of most of our software packages for interpretation of the data we have processed, and have 
put the processed (DFM) data volumes from a subcontractor (TransSeismic International) into a 3D visualization package for easier interpretation. In addition, we have 'tricked' a visualization package into accepting prestack data from a 2D seismic line, using offset as the second horizontal dimension, in order to investigate the significance of acquisitioninduced artifacts.

The software that we are using provides outstanding visualization capabilities, and we continue to develop approaches to viewing the data in ways that make interpretation and transfer of ideas straightforward.

\section{Technology Transfer}

Our web site is complete, and being updated regularly (http://www.geo.mtu.edu/spot). We presented a poster at the annual AAPG meeting in San Antonio, TX in April, 1999, and assisted in the preparation of a manuscript describing the Dynamic Fluid Method (Pisetski, 1999, published in THE LEADING EDGE). Short in-house presentations describing various details of the project have been made at industry partner offices (BP/Amoco) and consortium meetings (the Teal South group at the Energy Research Clearing House). With the current efforts in attribute evaluation coming to fruition momentarily, four upcoming technology transfer events are already planned:

- "Time-Lapse Seismic Petrophysics" - an overview talk to be presented at a workshop on Seismic Signatures of Fluid Transport, February 27-29, 2000;

- a presentation at the Society of Exploration Geophysicists (SEG) Summer Development and Production Forum on Quantitative Prediction of Reservoir Properties using Geophysical Data, May 14-19, 2000,

- an invited review paper on the seismic detection of fractured rocks, to be submitted to GEOPHYSICS in spring, 2000, and

- participation in a millennium review article on the state-of-the-art in geophysics (our contribution was in reservoir geophysics) for GEOPHYSICS, submitted. 


\section{Results and Discussion}

This section of the annual report first describes current results for each data set, then discusses these results and suggested interpretation as a whole.

\section{Crystal Field 2D seismic data, Michigan}

We made use of a 2D seismic line for which we had prestack (raw field record) seismic data, in order to evaluate the usefulness of such data for seismic attribute analysis, and to investigate the importance of seismic acquisition artifacts (the seismic acquisition 'footprint'). We also hoped to be able to actually use this line for attribute analysis over a field that had formed the basis of an earlier DOE-supported Class II project.

The seismic line had been acquired in 1986, and had been processed commercially for a good-quality poststack section, which had also been used in previous work by us. Our processing of the prestack data did not yield as good a result as the commercial processing, probably due in part to the extreme static corrections required (we do not have a good refraction statics program at our disposal). Even though the poor quality of our reprocessing resulted in a line that could not be used with confidence for attribute analysis, it did provide us with an excellent case for the study of acquisition artifacts because the line was irregularly sampled and because the incomplete statics could be considered as an additional acquisition-related problem. Figure 1 shows some displays of the seismic data in conventional format.
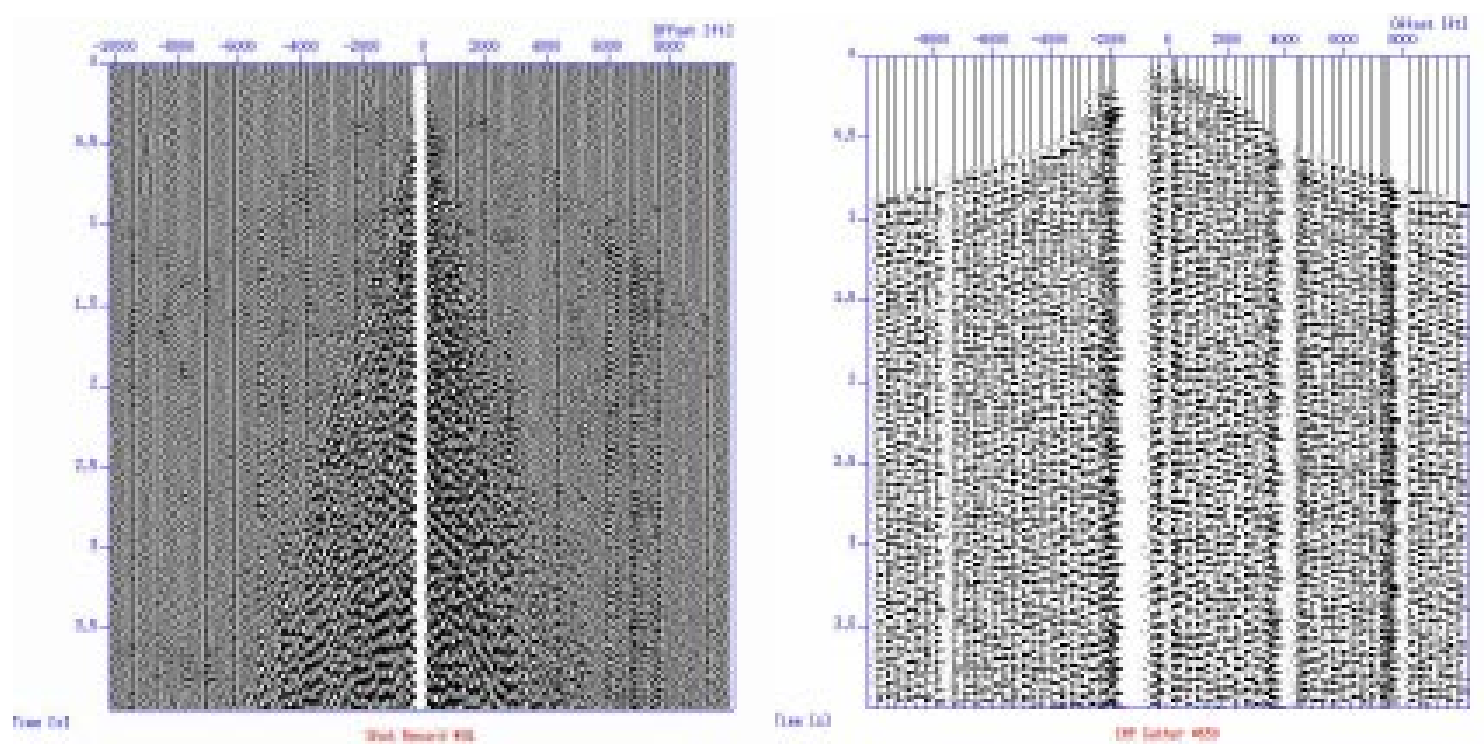

Figure 1: Left side: A shot gather of the Crystal field data; Right side: a CMP gather.

The Devonian dolomite reservoir comprising Crystal Field occurs at an early time in the seismic data, and the fold at this time is low, generally about 6 after mute. The details of the mute are important, because the ground roll can easily be summed into the stacked trace in some CMP gathers, and not in others, greatly affecting the amplitude and other attributes of the stacked data. The use of vintage data, acquired to identify prospects at 
one depth (in this case, much deeper) and used to investigate a different depth, should be discouraged. If we followed this line of investigation any further, we certainly would have found attributes that were meaningless in terms of reservoir properties.

We then turned to investigation of $3 \mathrm{D}$ visualization techniques for evaluation of $2 \mathrm{D}$ prestack data, by using rewriting the data as a $3 \mathrm{D}$ volume, with offset as the second horizontal dimension (CMP location is the first horizontal dimension, and time is the vertical dimension). In this way, we can quickly scan down the data (as a series of time slices) and across the data (in CMP gathers, shot gathers, or receiver gathers) and identify artifacts or anomalies of interest. Figure 2 shows one such set of displays in a perspective view.

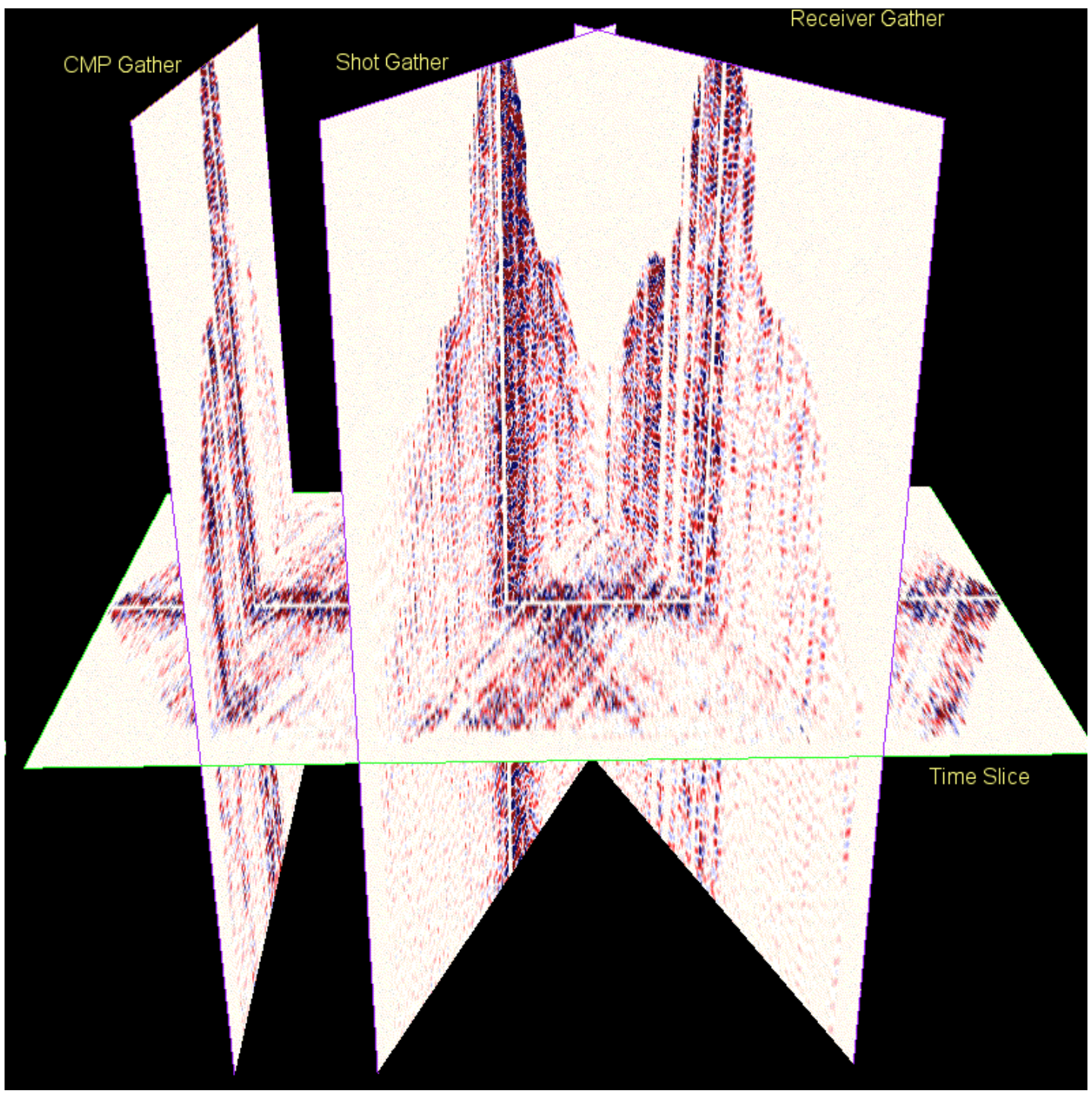

Figure 2: Three-dimensional view of a prestack 2-D line. One shot gather, one common-receiver gather, and one common-midpoint gather are shown along with one horizontal time-slice. The influence of acquisition-related artifacts is readily apparent, in the striping and banding of amplitudes, as indicated by the colors. This data were NMO-corrected and muted prior to display. 
We have used this (Crystal Field) data set to test various techniques, but will likely not pursue analysis of this set any further, other than to demonstrate the principles involved in recognizing and avoiding acquisition footprints.

\section{Stratton Field, South Texas}

The public-domain data set from Stratton field has been loaded into each of our main software packages, and has formed the basis for testing several methods of investigation. In particular, we have looked into the difficulty of imaging features that are below seismic resolution, in an effort to identify the channels known to be present in the volume. Some of the channels are readily seen, particularly at shallow levels, but most channels can only be inferred by correlation with well data and through recognition of subtle features on the seismic data. One of the shallow channels presents an interesting example of conflicting attribute evidence, as shown in Figure 3.
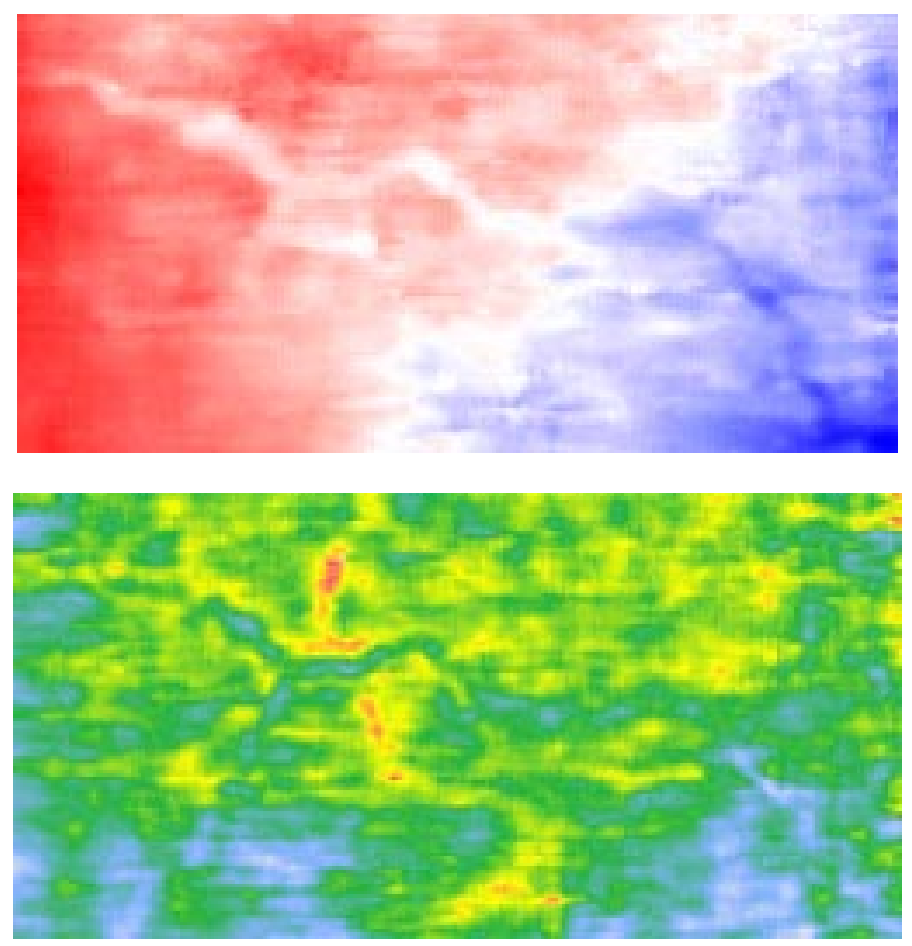

Figure 3: Shallow horizon in Stratton data showing apparent stream channels. The top figure is colored by time structure (deeper times are blue), and the bottom figure is colored by amplitude. The amplitude attribute is clearly indicating the presence of some feature not apparent on the time structure, and that also appears to have the morphology of a stream. See Figure 4 for a three-dimensional view of this paradox.

The conflicting evidence consists of two apparent channels, each visible by one attribute or another, along the same horizon. The time structure displays a channel that seems to trend NW-SE, while the amplitude display on that same horizon shows another apparent channel, running more or less N-S. A three-dimensional display is shown in Figure 4. 


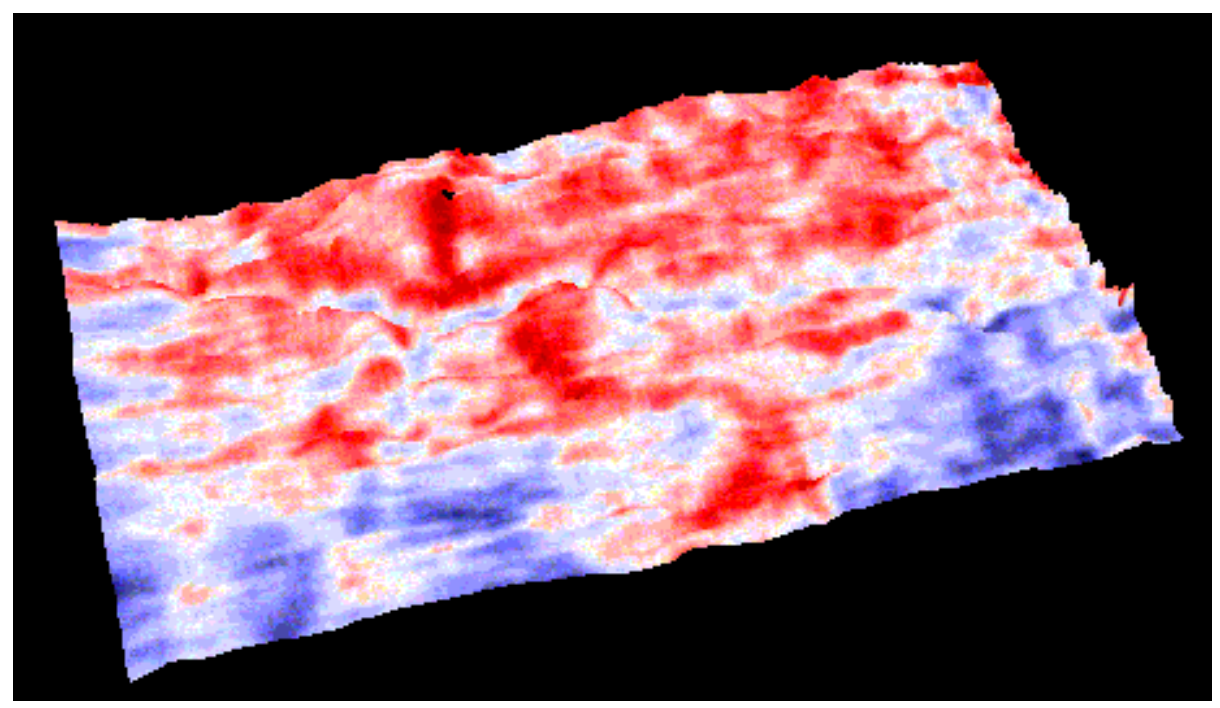

Figure 4: The same horizon as shown in Figure 3, from the Stratton data set. In this image, the threedimensional view has been rotated to provide a good perspective view of the time structure, and the channel can be seen as a local depression or trough trending from the upper left (NW) corner to the lower right (SE) corner of the image. The amplitudes on this time structure provide the coloring, and another feature, with the morphology of a channel but without an expression on the time structure, can be seen as a red sinuous body trending roughly N-S. The origin or significance of these two features is not yet clear.

The Stratton field produces from the Frio formation from reservoirs contained within a series of meandering channel-fill deposits. The Texas Bureau of Economic Geology (BEG), in a project supported by the Dept. of Energy and the Gas Research Institute, studied this field in some detail(e.g., Hardage et al, 1994), in an effort to use seismic data to aid in identifying sources of reservoir compartmentalization. They also have made a subset of the data available for public use. In their study, they found that seismic data could resolve very small channels at considerable depth, down to $10 \mathrm{ft}(3 \mathrm{~m})$ thick channels, $200 \mathrm{ft}(61 \mathrm{~m})$ in width at depths greater than $6000 \mathrm{ft}(1800 \mathrm{~m})$. They interpreted some channels in the time structures (assuming that they represent paleotopographic surfaces along which the streams flowed), and also observed some crosscutting amplitude features at some reservoir levels, which they presumed to be due to "residual effects from the deeper Vicksburg faults" (p.1655, in reference to reservoir level F39). The cross-cutting amplitude anomaly shown in Figures 3 and 4 of this report is in a very shallow horizon, and does not have an obvious relationship to features in strata immediately overlying or underlying it, bringing any presumed direct association with deep structure into question.

The BEG study used high-quality Vertical Seismic Profiling to provide very accurate well ties between the seismic data and the productive intervals. They then used those well ties to determine what part of a wavelet corresponded to the thin-bed reservoir interval. They tracked a horizon that was close to the reservoir interval, then extracted attributes for the interval that corresponded to the reservoir location; for example, they may have tracked a geophysically recognizable horizon that occurred at, say, $1586 \mathrm{~ms}$ at the well location, and then extracted the amplitude at the time that a reservoir interval occurred, say, $42 \mathrm{~ms}$ above that horizon. That extraction rarely occurred at a peak or 
trough in the seismic data, but at some other location within the wavelet. This approach is pictured schematically in Figure 5.

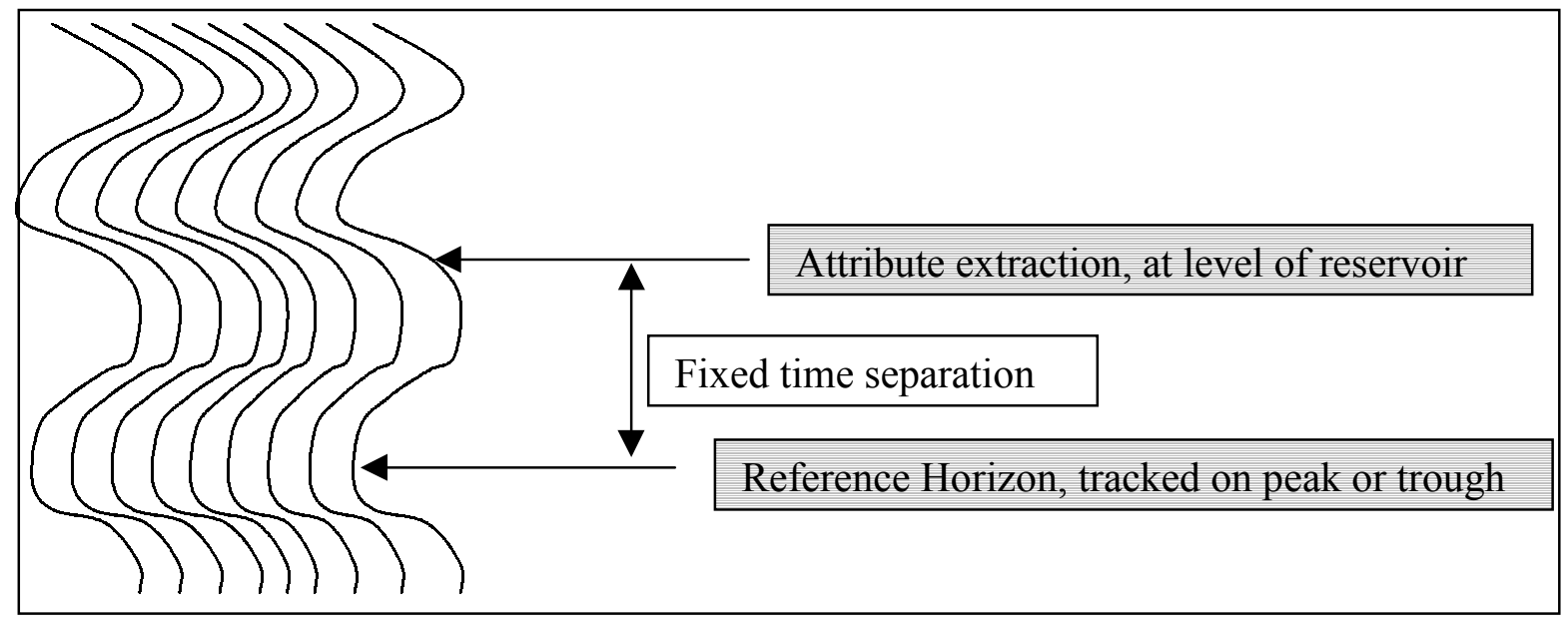

Figure 5: Schematic diagram summarizing approach used by the Texas BEG in Stratton field.

We have tried to duplicate this approach, with mixed success, probably due to the limited size of the public-domain data set, compared with the larger volume of data with which the BEG based their work.

We have extended this approach, however, to include a complete wave-shape matching routine. The BEG approach is straightforward, and readily accomplished on most workstation software packages. Newer techniques have become available to classify the seismic wavelets themselves into different categories, or 'facies,' depending on details of their shape. The technique we have applied is implemented in the commercially available package Stratimagic, which uses a neural-network approach to divide the waveshapes found in the interval being considered into a (user-specified) number of different 'facies.' The maps displaying the spatial locations of the different facies can often provide a picture of geologically meaningful features, such as channels or crevassesplays. We pursued this approach because the BEG approach indicates that subtle differences in wave character provide strong clues to the location of channels or to the compartmentalization of the reservoirs. Figures 6,7 , and 8 show examples of the output from this approach, using a shallow channel (the same horizon as shown in Figures 3 and 4) for investigation purposes. Unfortunately, none of the wells penetrate this feature, and we are presently not sure what lithologic properties are providing this seismic response. Additional facies classifications are underway on actual reservoir horizons.

These unsupervised classification schemes are useful as a first-look approach, but we are investigating the physical basis of attributes in this project, and feel that the seismic analysis is not complete without incorporating log data and models of lithologic variations into the interpretation. To that end, we have obtained a beta-test version of NexModel, a program provided by the company that markets Stratimagic, that will allow us to model variations of seismic waveshape from synthetics generated by varying log properties, and classify the facies according to the features we might expect to observe. 
We have also obtained additional completion and initial production data from the new operator of the Stratton field, allowing us to make better correlations with productivity.

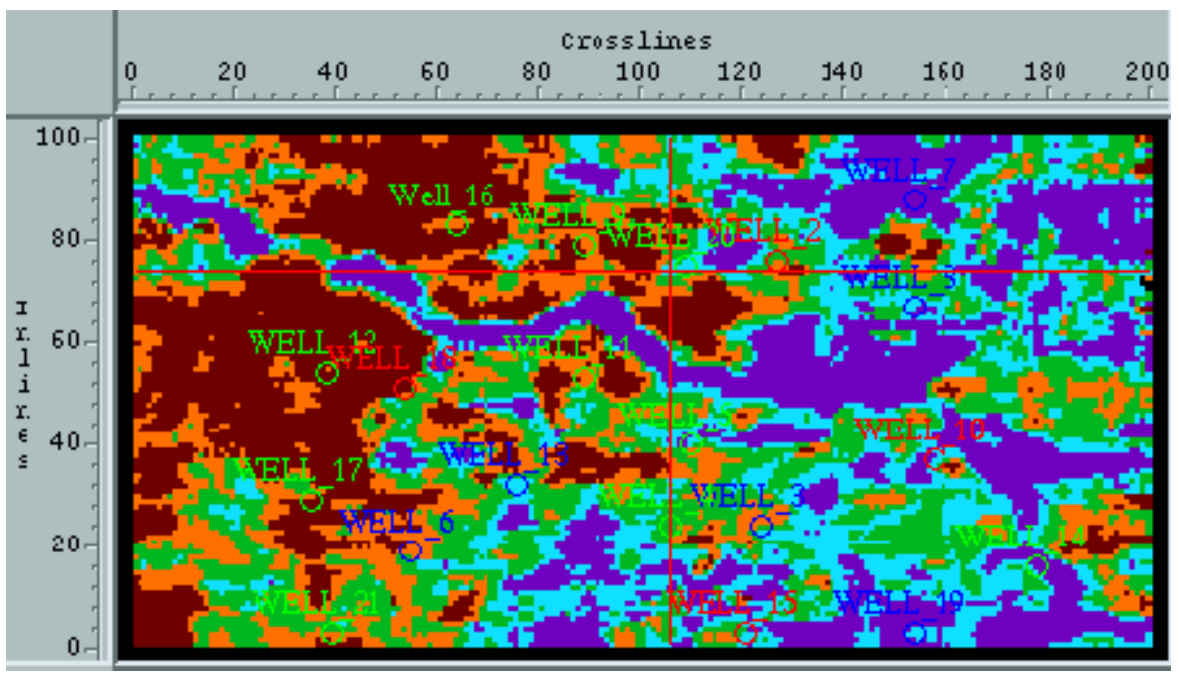

Figure 6: Seismic facies classification map of an interval near $840 \mathrm{~ms}$ in the Stratton data set.

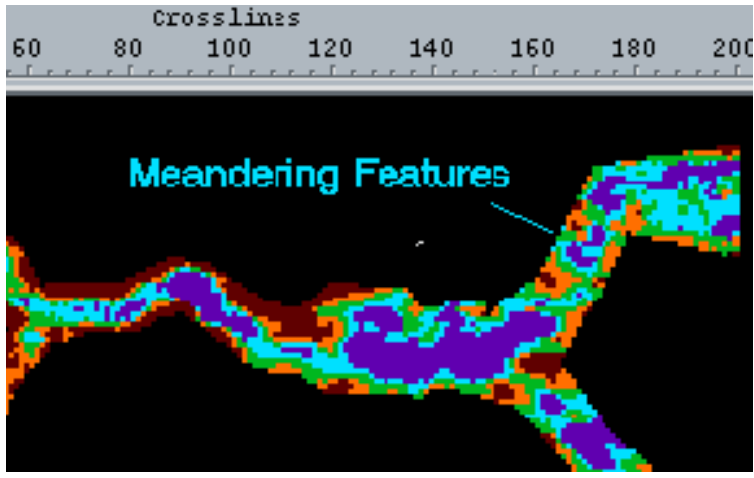

Figure 7: Cut-out region of channel, with detailed reclassification of facies within this channel.

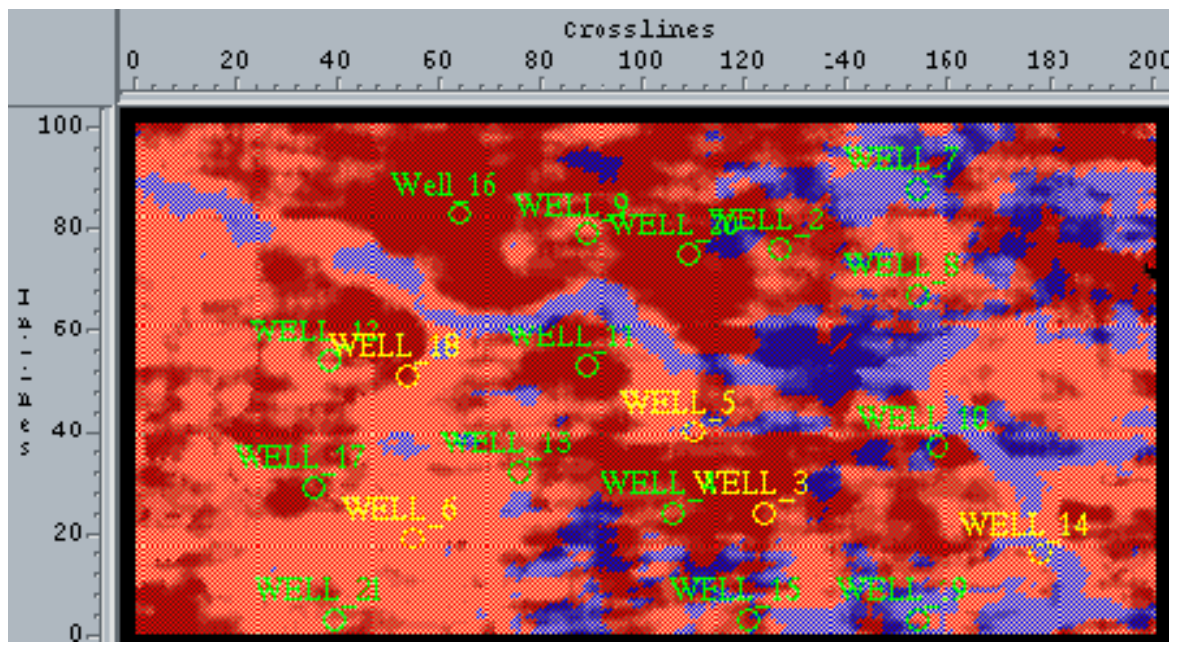

Figure 8: A combination of time structure and facies classification. in the Stratton data set. 
The Stratton data set has also been analyzed by our subcontractor, TransSeismic International, using their proprietary Dynamic Fluid Method (DFM). Their detailed report is provided as a separate report, and a discussion of their technique is provided in a later section of this report, but some summary statements are made here concerning their observations in the Stratton field. The DFM technique uses instantaneous frequency and amplitude, removing the quickly-varying trends in time by averaging along horizons or time slices, and subtracting those averages. The remaining differences in frequency and amplitude are combined in a special algorithm, intended to be indicative of effective pressure (total pressure minus pore pressure). The areas of low pressure (or decreasing pressure, as this is considered to vary with geologic time, and is a dynamic phenomenon) are generally colored red in their displays, and indicate prospective zones for accumulation of hydrocarbons. In some environments, such as fractured tight sands, they expect to find accumulations, particularly of gas, along the boundaries between the regions of increasing and decreasing pressure.

The DFM interpretation of the Stratton field has indicated the presence of at least one channel at about the $1250 \mathrm{~ms}$ interval; it is identified by the stress concentration resulting in the overlying and underlying strata as differential compaction occurred around the channel feature itself. They have concluded that the ancient streams have followed the edge of blocks present in the deeper Vicksburg strata, suggesting that movement on the Vicksburg faults continued at least through Frio time (and may continue even today). The summary figures supporting these interpretations are included here as Figures 9, 10, and 11 .

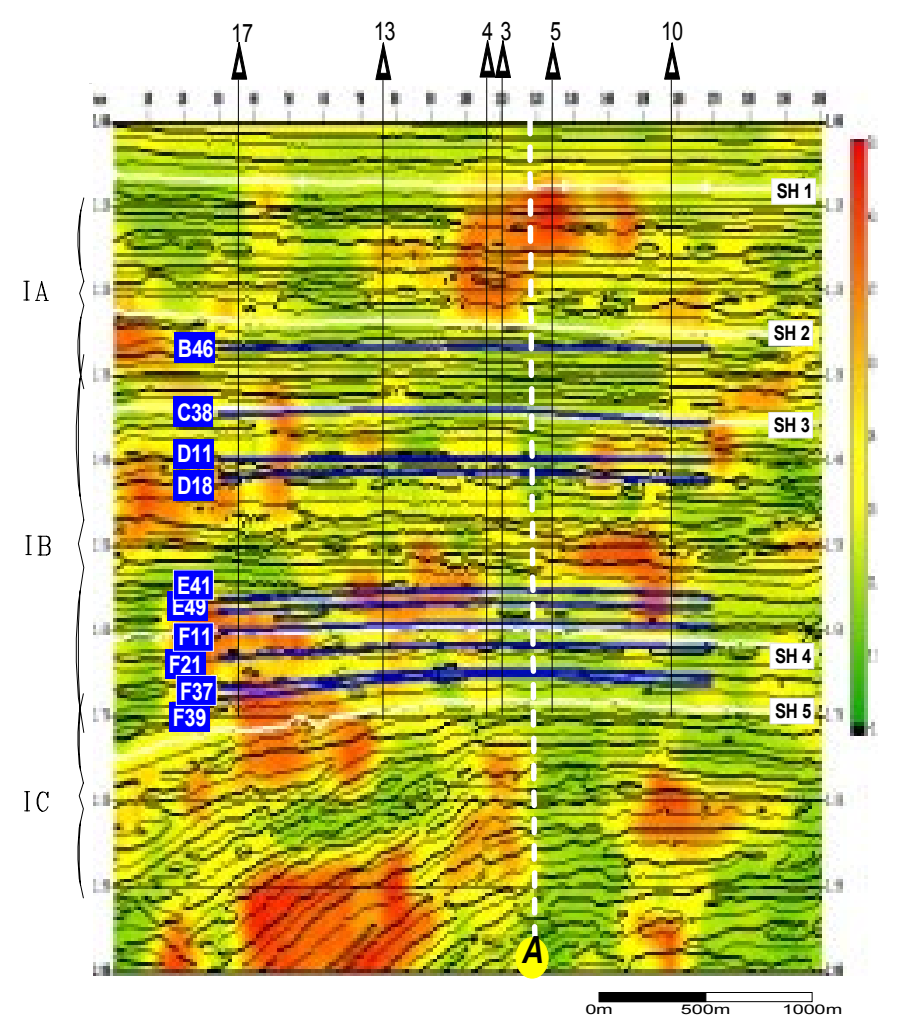

Figure 9: DFM results for Stratton field along one inline, showing regions of low effective pressure in red.. 


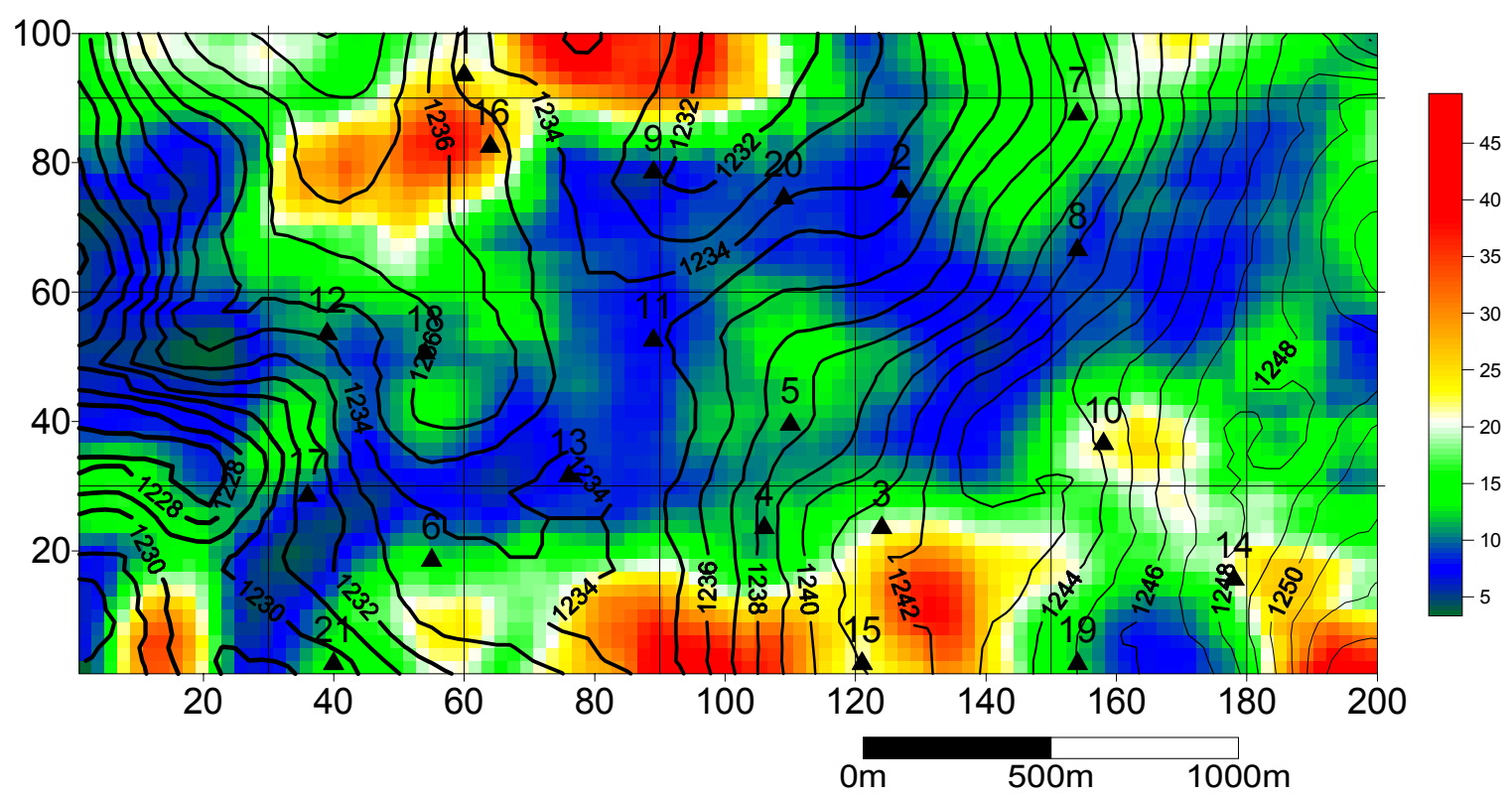

Figure 10: DFM results for Stratton field showing an apparent channel identified by its stress concentration (high effective stresses in blue) along an interval at about 1250ms, labeled SH2 on Figure 9. The time structure is shown by the contour lines.

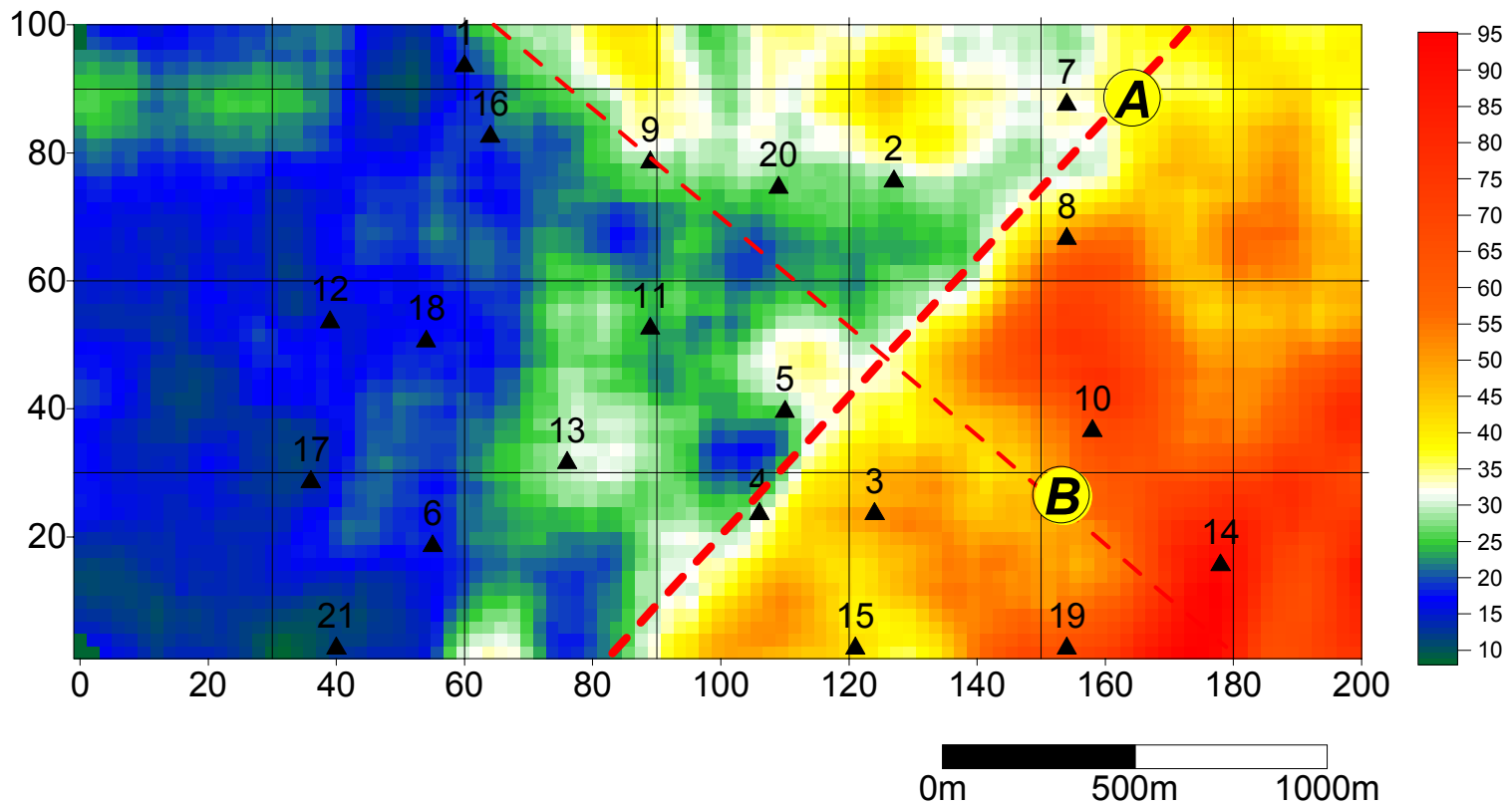

Figure 11: DFM results for Stratton field showing the block structure inferred in the deeper Vicksburg formation. TransSeismic International has concluded that these deep-seated structures control the development of channels throughout later times, and their boundaries provide pathways for fluids. 


\section{Boonsville Field, North Texas}

The Boonsville public-domain data set has been studied in some detail by our group. We have developed a log-classification scheme that has been used to tentatively assign geologic facies to the various environments found, as shown in Figure 12.

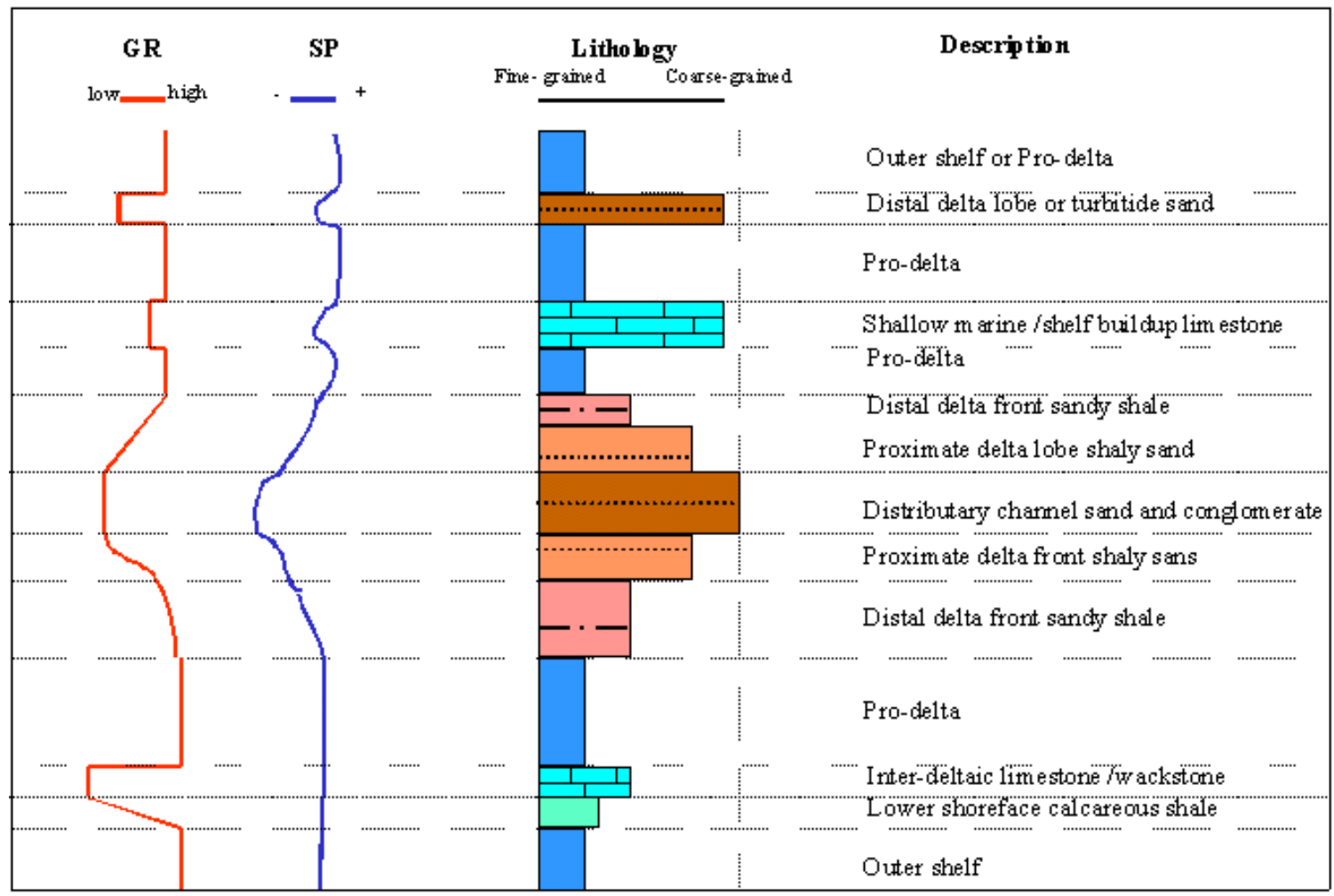

Figure 12: Caddo formation log-based classification scheme developed in this project.

This classification scheme has resulted in the determination of distribution of geologic facies as shown on the map in Figure 13. A seismic wave-shape classification was also conducted for Boonsville, using the seismic wave-shapes as shown in Figure 14. The seismic facies derived from this classification resulted in the map shown in Figure 15, where the seismic facies are also correlated with the geologic facies as determined from the log data. Figure 15 presents our current combined interpretation for the Boonsville depositional environment at Caddo time. Production information is available for this area, and has yet to be incorporated into our interpretation.

The Boonsville data has also been processed and interpreted with the DFM technique by a subcontractor, whose complete report is provided separately, together with their interpretation of the Stratton field. A brief summary of their conclusions and additional visualization of the results are presented here, together with some comparisons with production information. 


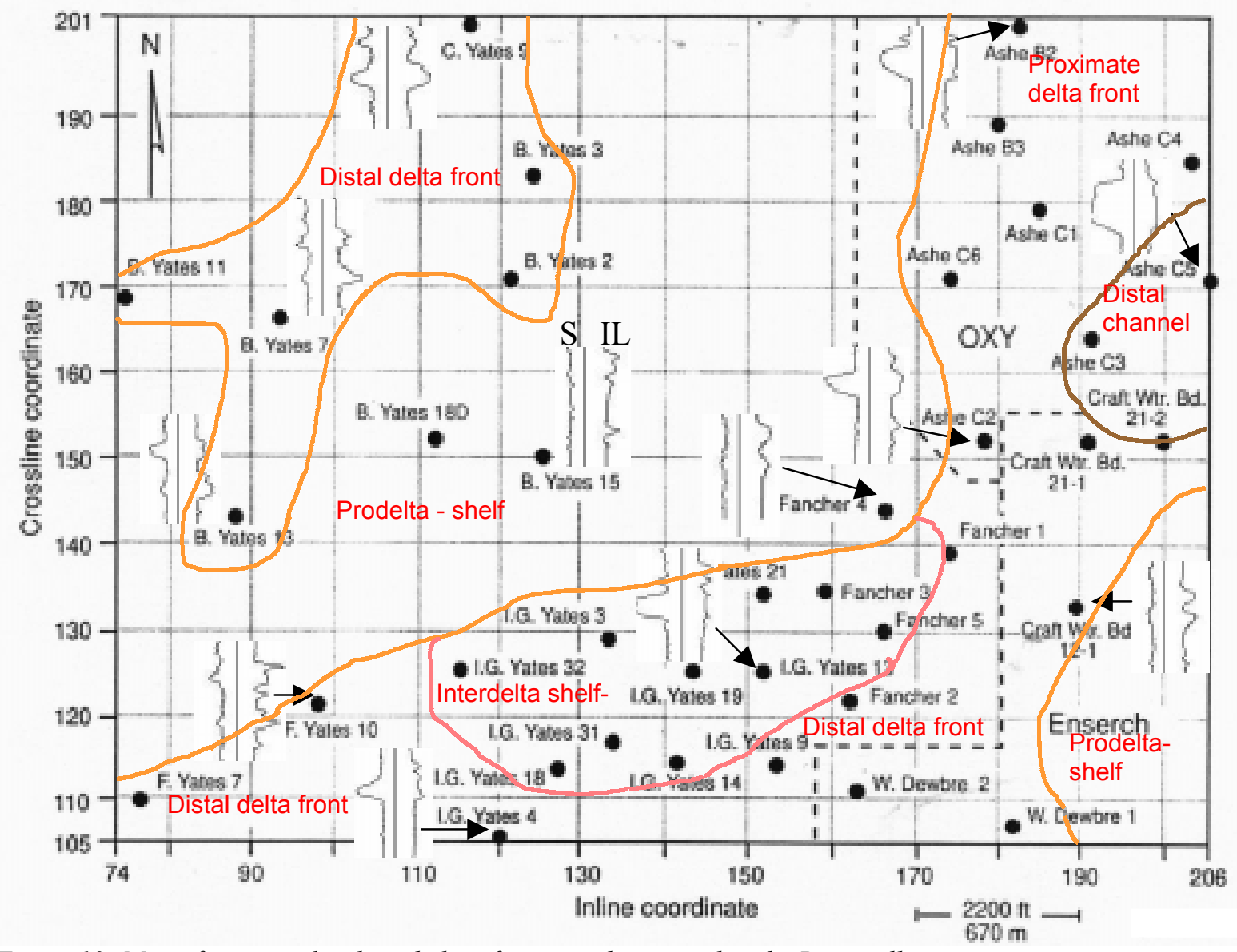

Figure 13: Map of tentative log-based classification scheme used in the Boonsville interpretation.

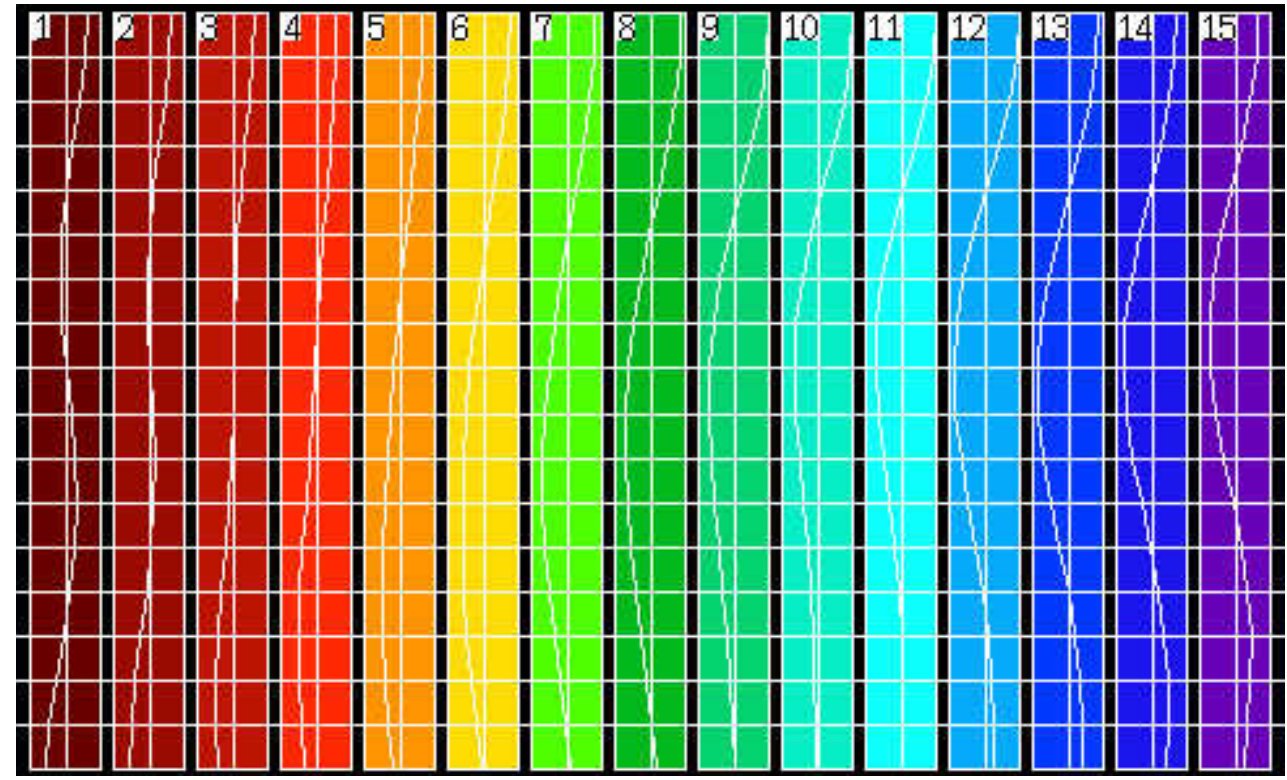

Figure 14: Seismic waveshapes used in the seismic facies classification. 


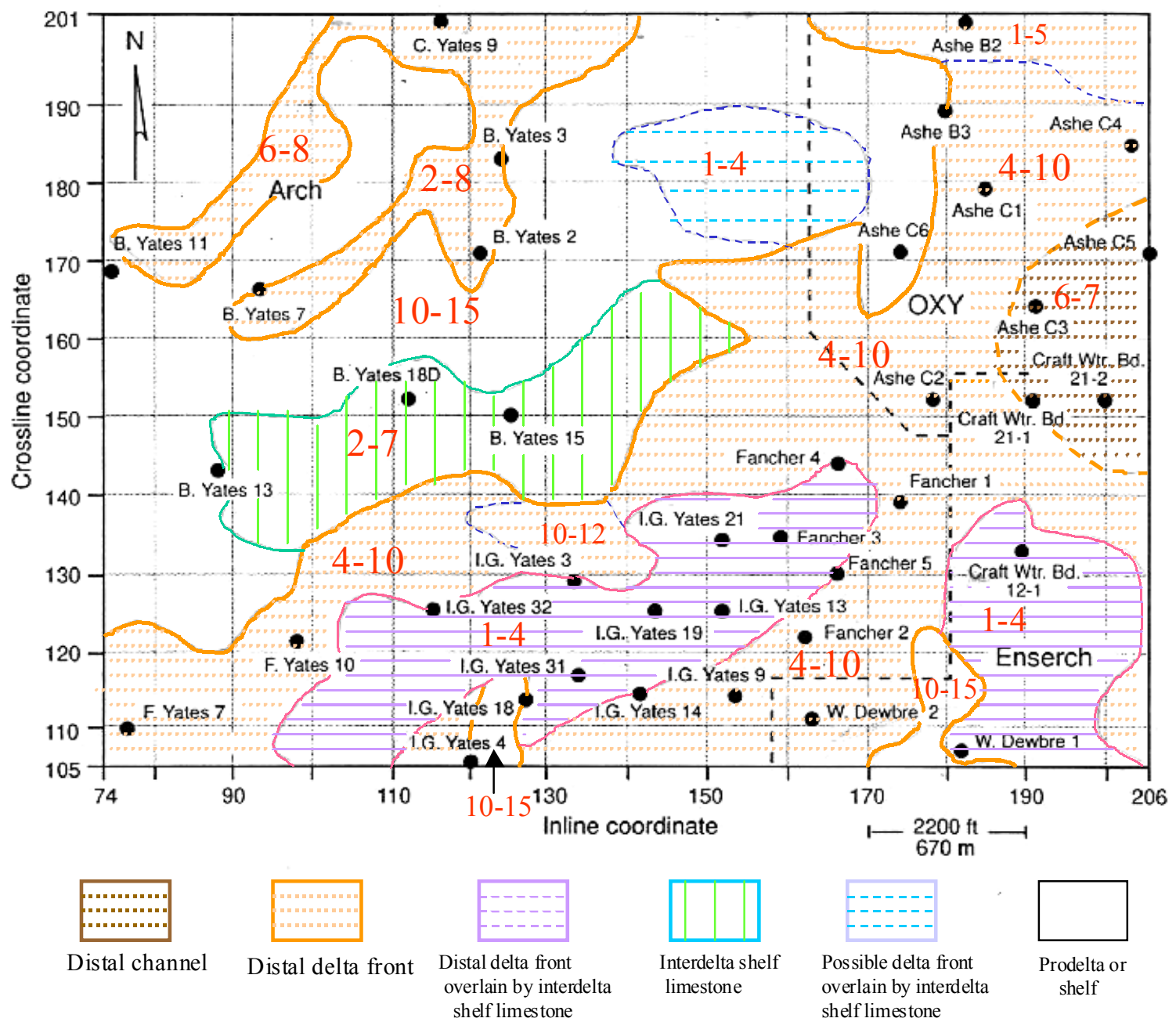

Figure 15: Seismic facies classification combined with the log-based geologic interpretation in Boonsville.

The results of the DFM analysis conducted by TransSeismic International entail an interpretation scheme that is different from that used for Stratton. In Boonsville, the migration paths used by hydrocarbons are sought, in part because the rocks are harder and the fluids require enhanced fracture paths for transport, and in part because the karsting that occurred in deeper intervals has created these pathways. In the subcontractor's viewpoint, the potential productive zones could either be in the regions of decreasing effective pressure or along the boundaries between blocks of decreasing pressure and of increasing pressure. Figure 16 shows a three-dimensional view (created at MTU using data provided by the subcontractor) of the decompressing regions, shown in red. Figure 17 shows the relationship of pressures in the productive Caddo zone with the initial oil productivity of wells in the field, from that zone. 


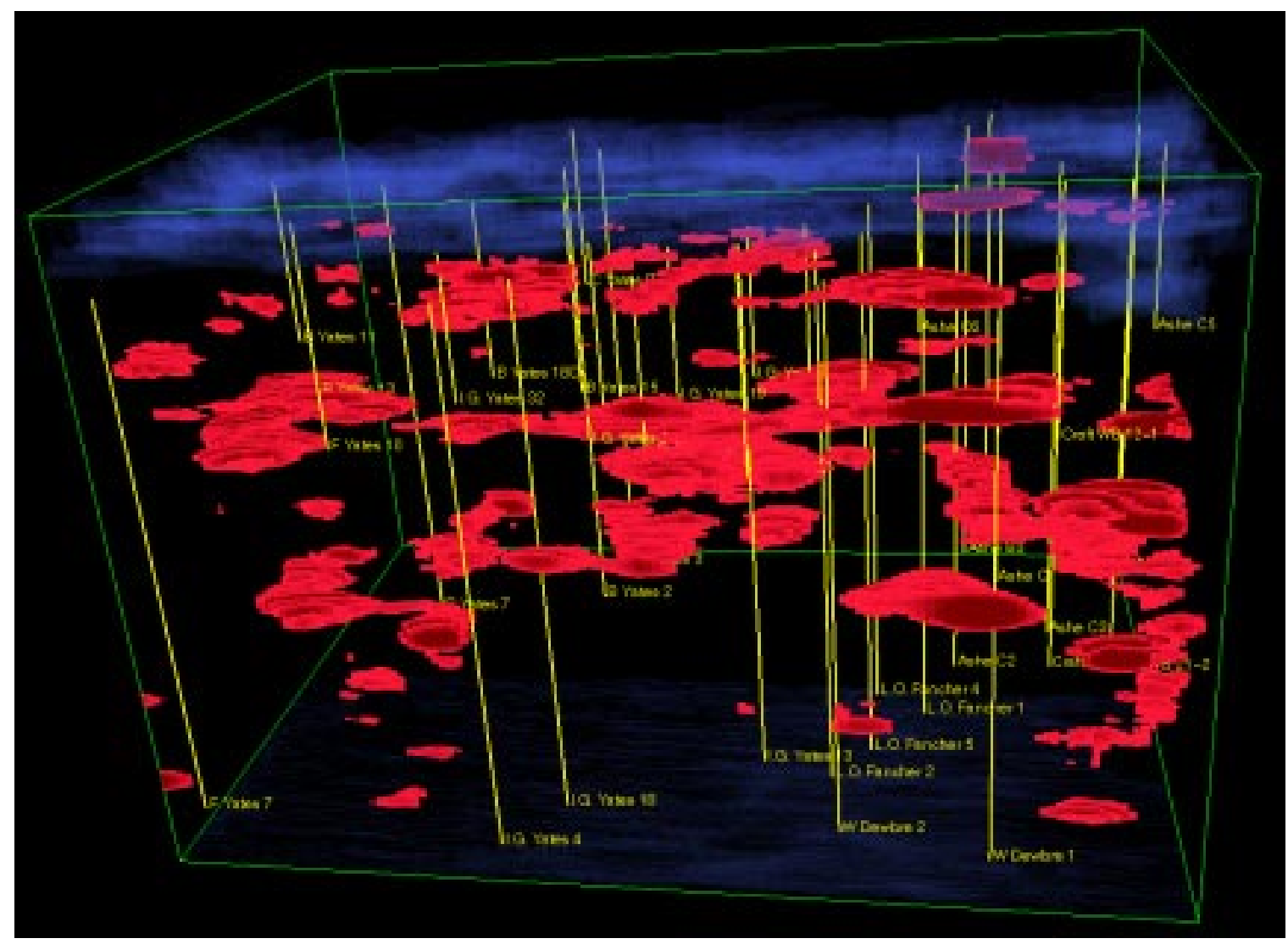

Figure 16: Three-dimensional image of the DFM results for the Boonsville data set, processed by TransSeismic and imaged at MTU; the red colors represent areas of decreasing effective pressure, presumed to have greater potential for hydrocarbon accumulations in the DFM approach.

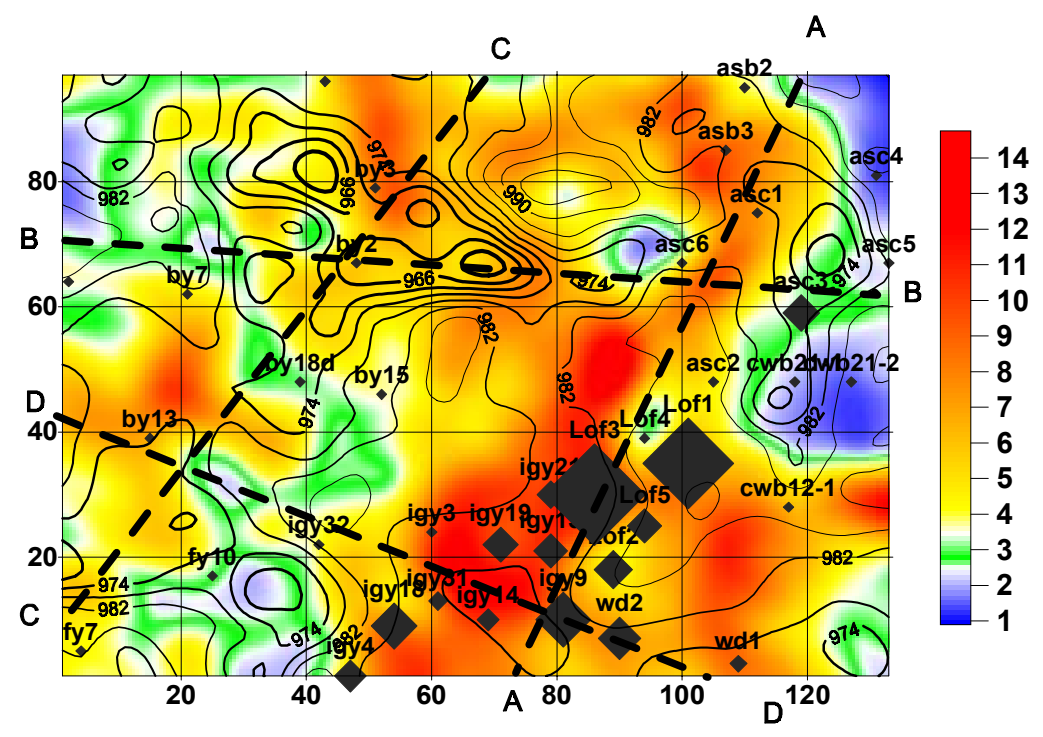

Figure 17: DFM results for the Caddo interval (red represents decompressing regions). The dashed lines indicate block boundaries interpreted by TransSeismic from the data. The size of the diamond symbols is proportional to the oil recovery from the Caddo interval from wells in the field. 


\section{Wamsutter Arch, Wyoming}

The original agreement between Amoco and Michigan Tech for collaboration on analysis of data from the Almond formation of the Wamsutter Arch area, Wyoming, is being honored by the new company, BP/Amoco, with enthusiasm. In spite of office moves, personnel changes, and other upheavals associated with a merger of this magnitude, we have found that the geoscientists, engineers, and managers associated with the project are continually supportive of our work, and provide us with time, data, and advice, as we progress.

We received a high-quality 3D seismic survey over the Creston Nose portion of the 'Sweetspot' area. See Figure 18 for location. We have also received log data and initial production information for many of the wells, and checkshot information for a well outside of our area, but nearby. Velocity measurements have been made on core available in Tulsa, using a handheld device borrowed from the Colorado School of Mines. These measurements show a high degree of anisotropy (transverse isotropy) in compressional-wave velocities wherever silt layers are encountered, and will help provide us with an estimate of fine-scale vertical velocity variations. Raw data used in published reports have been made available to us for outcrop analogs of the reservoir rock. These measurements include densely-sampled porosity and permeability values.

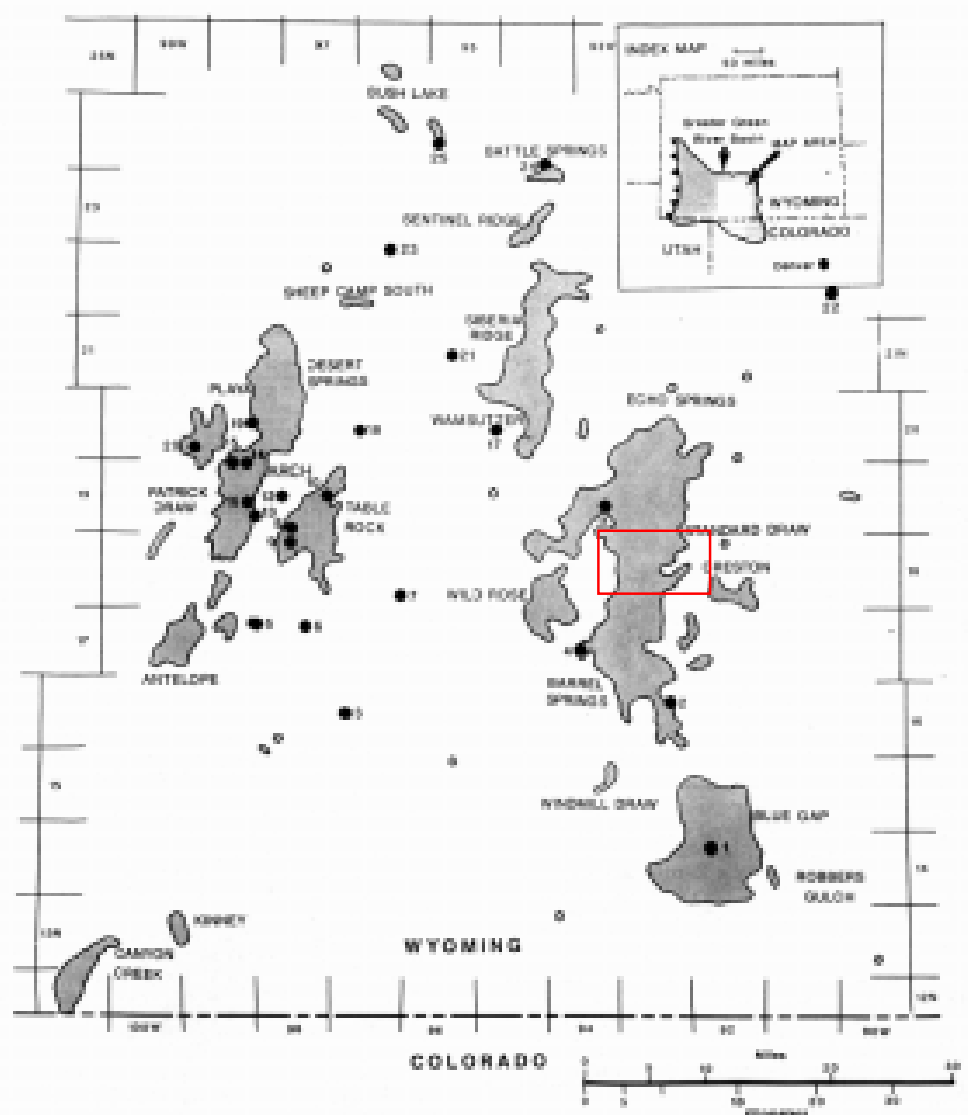

Figure 18: Location of the Wamsutter survey area. After Stephenson et al, 1987, and Keighin et al, 1989. 
Our initial interpretation in this area has consisted primarily of tracking horizons, trying to identify a good well-to-seismic tie, inverting the seismic data for acoustic impedance, and approaching the wealth of data with various geostatistical techniques. Figures showing details of this proprietary data set can not be made available to this report at our current preliminary stage of interpretation, but some discussion of the observations we have made can be provided here. The part of the geologic section containing the productive zones represent a near-shore and offshore sand bar facies during a brief hiatus or regressive period within an overall transgressive sequence (see Figure 19).

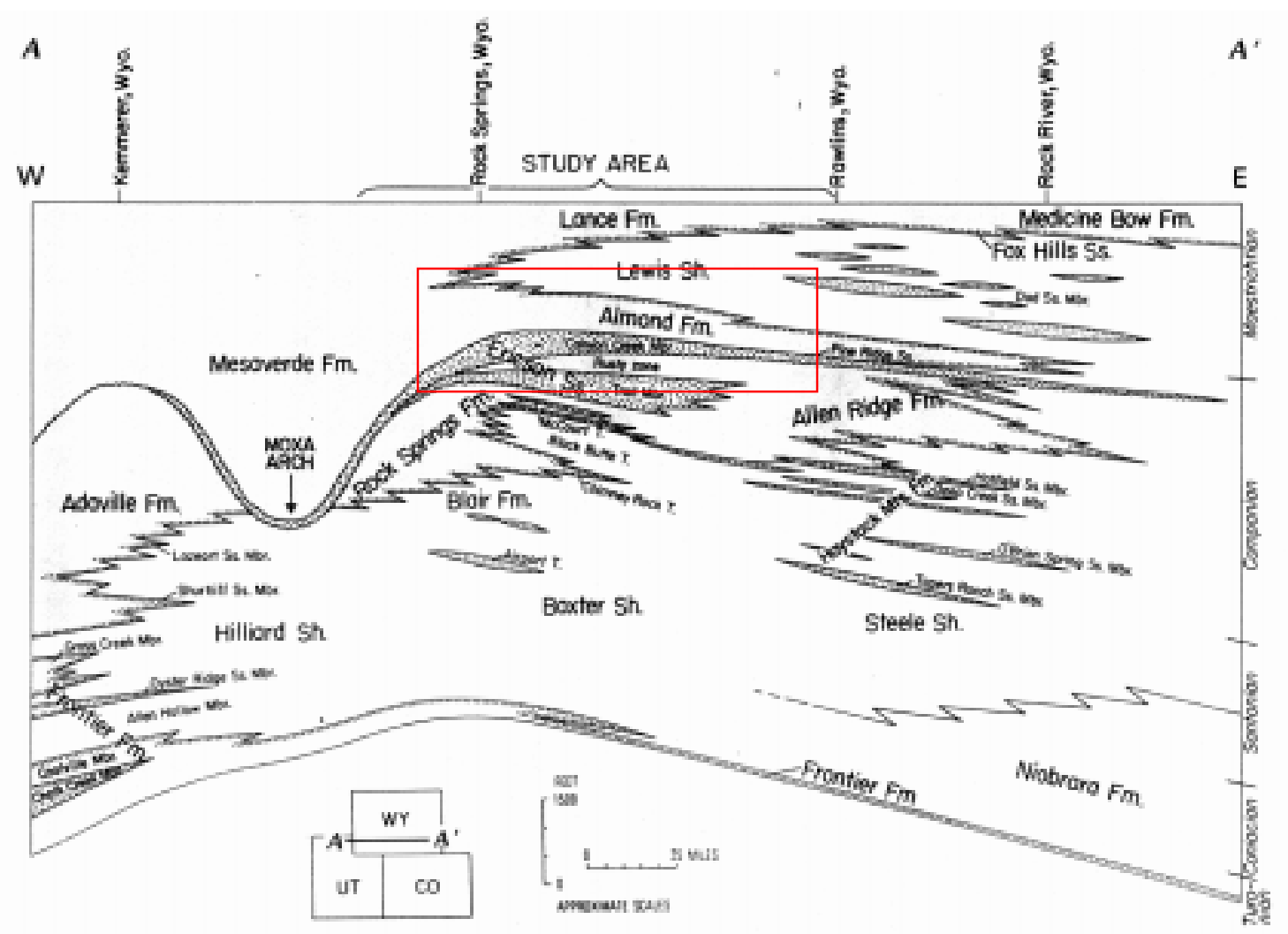

Figure 19: Schematic cross-section (after Roehler, 1990), showing the Wamsutter area of study.

There are two main features of the data that will make working with this field a challenging task: the rocks are high-velocity, low-porosity tight sandstones (providing little direct information about fluid content from seismic data); and the formation is finely layered, alternating with low-velocity coals and silts (producing wavelet tuning and interference effects in the data that tend to overwhelm a lithologic signature). It turns out that the quality of the processed data strongly affects our ability to resolve the productive zones; there are two, nominally similar, seismic data volumes covering our area. At first glance, and from most quantitative measures, they are virtually identical; but a closer inspection reveals that discrimination certain features is possible on one data set, but not likely to be practical on the other. Figure 20 shows an example of the current quality of the synthetic seismic match on one line in the volume. 


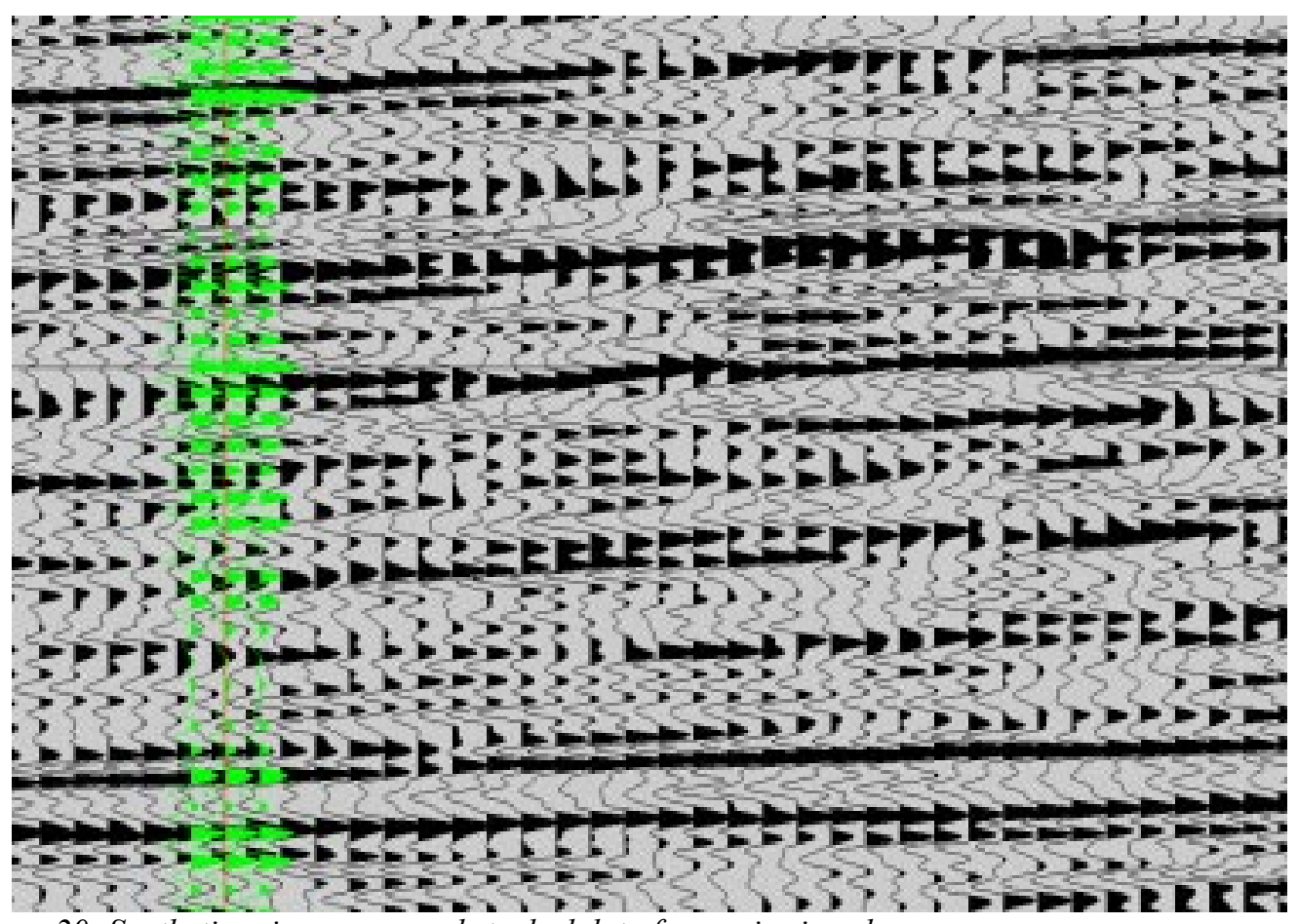

Figure 20: Synthetic seismogram and stacked data from seismic volume.

Using the seismic data set containing the finer details, we have made some interpretations on one horizon that leads us to feel that it is possible to identify lithologic differences from the attributes. Two histograms are shown in Figure 21, indicating that there is a natural separation of the (amplitude-based) attributes in this area.
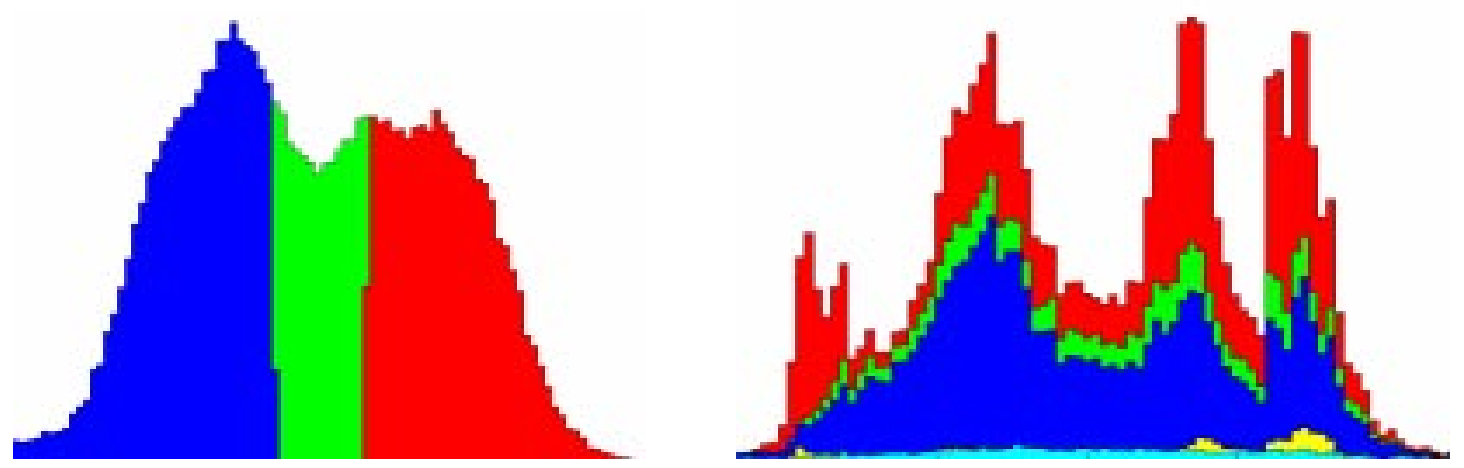

Figure 21: Two histograms of specific simple attributes from the Wamsutter seismic data.

\section{Teal South, Offshore Louisiana, Gulf of Mexico:}

The Teal South field lies offshore of Louisiana about 70 miles south of Morgan City. It is a fairly small field, operated by Texaco, that produces from more than one horizon. Texaco chose that field for a time-lapse study because it was expected to deplete quickly, and could provide useful information for evaluating time-lapse techniques within a few years. After their initial time-lapse study, Texaco offered the opportunity to study oceanbottom multi-component seismic time-lapse techniques to the industry in general, 
through a consortium organized by the Energy Research Clearing House (ERCH). That consortium has grown to include a number of producing companies and service companies, as well as a few universities (additional information can be found on the ERCH web site: http://www.erch.org). Our involvement in the project, supported through this contract with the Department of Energy, is to analyze the 'legacy' seismicstreamer data for the physical basis of the seismic attributes (this is a conventional 'bright-spot' play), and to predict the observations expected from the time-lapse studies. If we have calibrated the attributes properly, our predictions should be viable; if the predictions are incorrect, then we must not have calibrated the attributes appropriately. An image of the difference volume found by Texaco in the first phase is in Figure 22.

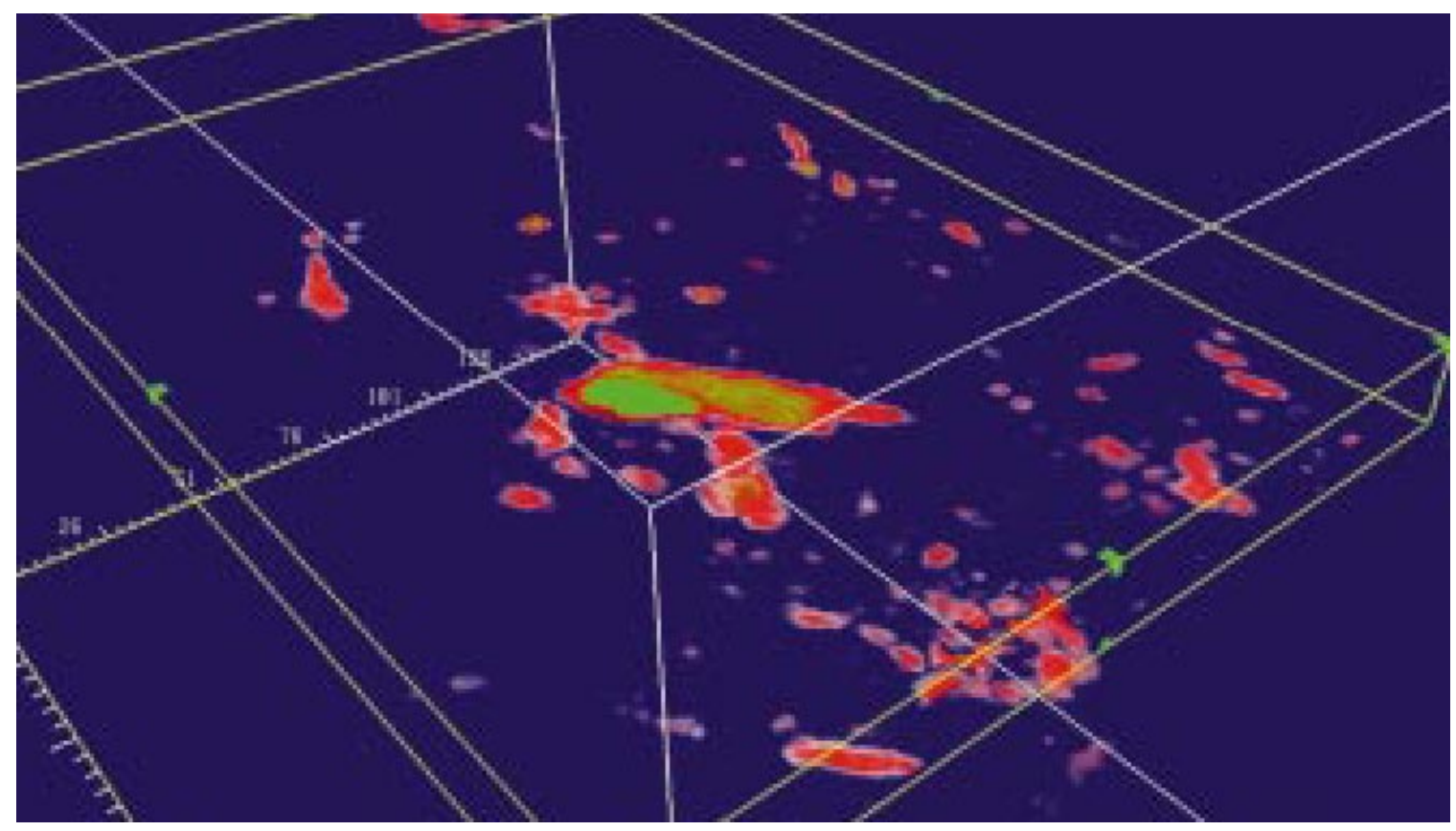

Figure 22: Three-dimensional image of a time-lapse difference volume found by Texaco during the first phase of the Teal South project. Bright colors indicate a change in reflection amplitude. From Ebrom et al, October 1998, THE LEADING EDGE.

One of the techniques of most interest to us for the calibration of these attributes in a thick-bedded interval is inversion for acoustic impedance, and we have started our processing of Teal South data with this technique. Inversion should provide the actual impedance values within the formation, not just the character of a reflection event that occurs at the top of the formation; as such, it is more tightly linked to the lithology and fluid content than a simple reflection seismic volume. In order to obtain accurate impedances, an excellent tie to well data must be accomplished first; we have just now received sufficient well data to perform this step of the process, but have already obtained a 'band-limited' inversion volume. One of the most critical steps in inverting seismic data is the determination of the seismic source wavelet present in the data after recording and processing; this also enhances the ability of the inversion process to effectively remove tuning artifacts in thin beds, and improves resolution considerably. The proponents of inversion argue that horizon attributes should be picked from horizons that have been tracked on inverted data, not on typical stacked and migrated data, because the 
inverted data has had most tuning effects removed. Even though we have currently only obtained a band-limited inversion, we can examine the effects of tracking horizons by posting an horizon that had been obtained by tracking on stacked and migrated data onto the inverted (band-limited) seismic volume; such a comparison can be seen in Figure 23.
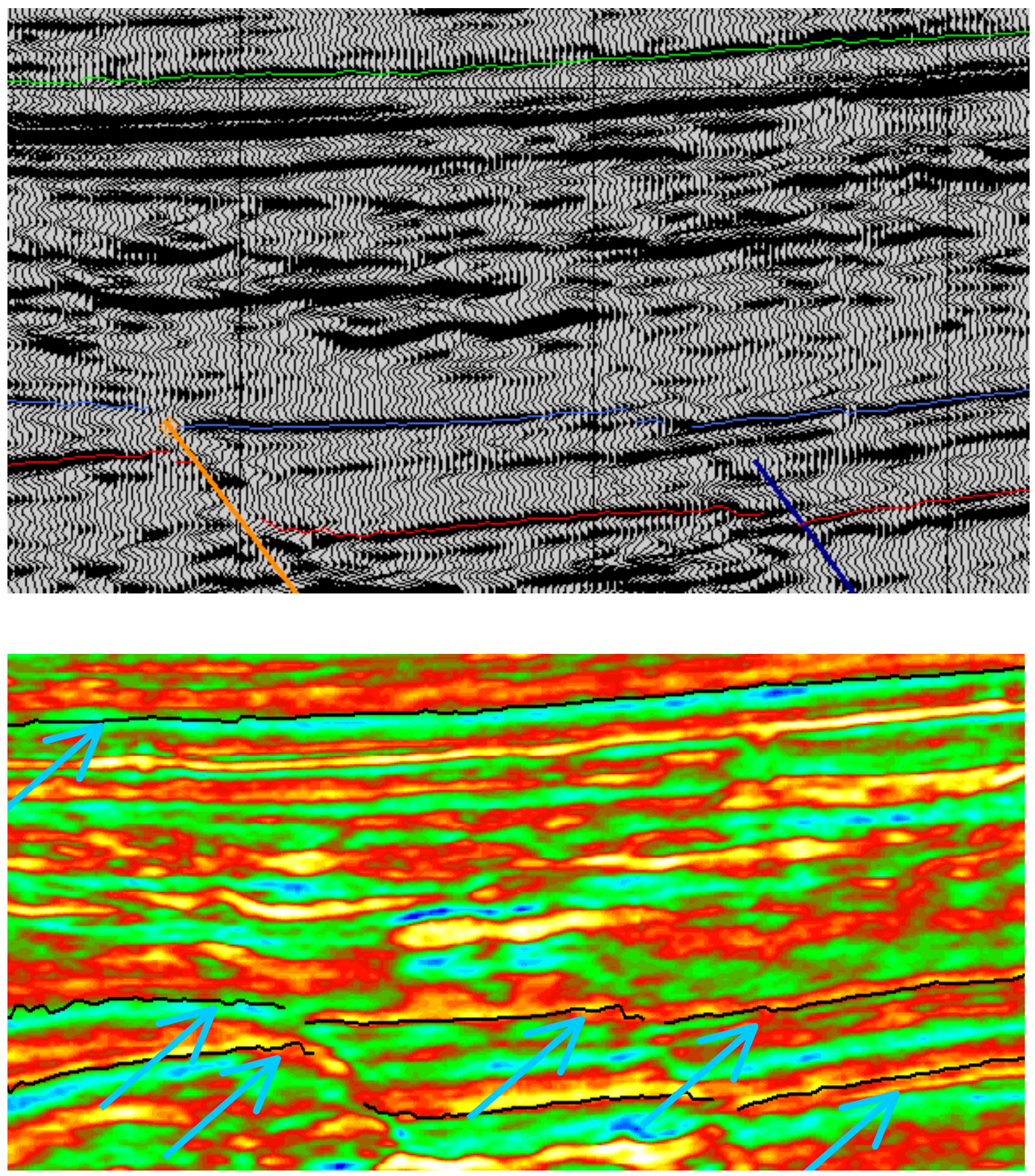

Figure 23: Top Figure shows original (migrated) seismic data, with tracked horizons superimposed in color; bottom figure shows (band-limited) inverted data, with the same horizons superimposed in black. The increased bed-definition capabilities of the inverted data will enable an improved pick for the tops of the horizons, particularly in areas that are indicated by the bright arrows. 


\section{Discussion of the DFM technique:}

The Dynamic Fluid Method (previously also translated as the 'Dislocation Fluid Model') was developed by Dr. Vladimir Pisetski of the Urals Mining Academy, in Ekaterinburg, Russia. The technique is patented, and Pisetski's USA-based company, TransSeismic International, is licensed to perform the DFM analysis. The DFM approach is both a computational technique and a conceptual interpretational technique. In this report, we are primarily concerned with the computations; many additional details can be found in their complete report, submitted separately.

The DFM computations are based on seismic attributes, particularly the instantaneous frequency and instantaneous amplitude, combined in such a way as to remove the average values along horizons or time-slices, and to enhance those aspects presumed to result from open cracks. In essence, the value of instantaneous amplitude (or frequency) is normalized at every point along the horizon (or time slice) by the average value along that horizon. These relative values are presumed to correspond more to the differences in physical state of the rock along the horizon than the original total value, which in turn correspond more to the change in lithology vertically in the section. That is, the lithologic differences generally sought through reflection seismology are in effect removed, by normalizing by the average values (along horizons or time-slices) of the attributes. The DFM method presumes that those differences remaining are indicative of open fractures, which in turn result from 'decompression' of blocks of rock, due mostly to unloading and differential compaction.

The specific attributes of instantaneous frequency and amplitude are combined in the following equation

$$
\theta_{i}=\left[\frac{A_{i}}{\widetilde{A}_{i}}\right]^{b}\left[\frac{\widetilde{\omega}_{i}}{\omega_{i}}\right]^{c}
$$

where the subscript $i$ refers to the $i$-th reflection point, A refers to the instantaneous amplitude, $\omega$ refers to the instantaneous frequency, and the tilde $\sim$ indicates an average value. The powers $b$ and $c$ are fitted to the data by the investigator, in an effort to best make the term $\theta$ correspond to effective pressure as indicated by other information. Their report, submitted separately, provides more details on the DFM procedure to relate this parameter, quantitatively, to pressure.

\section{General Discussion}

Even in areas where the simplest seismic attributes seem to correlate well with reservoir properties, we have seen that wavelet tuning and other effects have obscured the true physical relationships sought by the investigator. Although simple attribute analysis may work in many environments, it is partly due to simple luck that these other effects are not overwhelming; we suspect that these effects are often interfering with the analyst's ability to accurately predict reservoir quality in nearly all environments. At this point in our 
study, we are investigating several specific avenues to improve the relationship of seismic attributes with reservoir properties, including, but not limited to:

- $\quad$ seismic wave-shape analysis (and its calibration at wells),

- inversion for acoustic impedance,

- improved handling of thin-bed interference in synthetic seismogram generation, and

- improved conceptual models of seismic petrophysical procedures.

The first two of these topics have been discussed in the presentation of results from specific fields. The third and fourth topics are presented briefly now.

We know that the thin-bed problem is not handled properly in the construction of synthetic seismograms. A normally incident seismic wave responds to a time-average of the velocities when the wavelength is small compared with the thickness of the beds (this is the basis of ray theory, and is intuitively apparent); most synthetic seismogram programs assume this relationship for all bed thicknesses. But when the bed thickness is small compared with the seismic wavelength, the property to be averaged is not the velocity, but the modulus; this has been known to geophysicists since at least 1962, when George Backus published a paper on thin-bed anisotropy. For vertical incidence, the arithmetic is easy: average the P-wave modulus rather than the velocity for a blocking of thin bed properties. For non-vertical incidence, the arithmetic becomes quite complex, but is well-known. We are investigating the precision with which a seismic wavelet can be represented by just one frequency/wavelength while obtaining an accurate averaging of moduli and velocities; that is, should we be using a sort of sliding scale for the blocking depending on the bandwidth of the wavelet, rather than just one wavelength, or will one wavelength (for blocking purposes) suffice? We are also investigating the offset-dependence of this blocking and the inherent anisotropy that results; just how important is this offset dependence, and should it be modeled in routine synthetic seismogram calculations.

The seismic petrophysical models that are currently in use throughout industry often ignore a variety of well-understood phenomena. For example, the dry-frame modulus of a rock is strongly dependent on pressure. We are pursuing avenues of predicting that dependence from simple logged measurements. As another example, the modulus of the oil remaining in a reservoir after gas has been produced is much higher (the oil becomes 'stiffer') than it was when gas was still in solution; this is almost always ignored in backof-the-envelope calculations, although it can strongly affect the results expected. 


\section{Conclusions}

The project, "Calibration of Seismic Attributes for Reservoir Characterization," is on schedule as planned. We are currently studying four fields rather than the three initially promised, and are using more-sophisticated software suites than initially planned. Data have been received for all of the fields, and additional data has been received when requested. Our study is still in its beginning stages, but many tentative conclusions have been reached.

- Simple or conventional seismic attributes should be considered as 'proxies' for more complex phenomena, such as wave shape, which is itself a result of a variety of phenomena, such as lithology, bed thickness, etc.

- Wavelet tuning appears to lead to tracking of horizons on conventional (migrated) seismic data that will differ from tracking that would be obtained from inverted data.

- Certain petrophysical properties of rocks and hydrocarbon fluids are not always being modeled properly, and routines should be established for their proper application.

- The nature of the seismic source wavelet (after recording and processing) is perhaps the single most important piece of knowledge required to perform highly accurate interpretations in a quantitative manner.

- Certain combinations of seismic attributes, when applied in an intelligent and petrophysically driven manner, may provide keener insight to particular formation properties than any single attribute alone.

- Some of the wavelet effects may become apparent in data volumes specifically processed for wave-shape similarity, such as coherence or variance; for details in frequency content, such as spectral decomposition; for seismic facies analysis (supervised or unsupervised); or for spatial differences of instantaneous attributes, such as the DFM technique.

- For most of the techniques applied or in common use in the industry, the actual physical mechanism relating the seismic attributes to reservoir properties remains to be determined with confidence.

The second year of this project will see the further development and testing of approaches designed to properly treat these observations, using the four data sets currently in hand. The third year of the project will be occupied in testing the approaches on at least one different data set, and on improving the approaches for general use by others. Efforts in determination of the physical relationship of attributes to reservoir properties will continue. 


\section{References}

Ebrom, D., P. Krail, D. Ridyard, and L. Scott, 1998, 4-C/4-D at Teal South, THE LEADING EDGE.

Pisetski, V., 1999, The Dynamic Fluid Method, The Leading Edge.

Roehler, H.W., 1990, Stratigraphy of the Mesaverde Group in the Central and Eastern Greater Green River Basin, Wyoming, Colorado, and Utah: U.S. Geological Survey Professional Paper 1508. 


\title{
List of Acronyms and Abbreviations
}

\author{
2D -------------- Two dimensional \\ 3D --------------- Three dimensional \\ AAPG ----------- American Association of Petroleum Geologists \\ BEG ------------- University of Texas Bureau of Economic Geology \\ CMP------------- Common Mid-Point \\ DOE ------------- United States Department of Energy \\ DFM------------- Dynamic Fluid Method \\ ERCH ----------- Energy Research Clearing House \\ MTU ------------ Michigan Technological University \\ NMO ------------ Normal Move-out \\ SEG ------------ Society of Exploration Geophysicists \\ USA ------------ United States of America
}

